\title{
Estratégia metacognitiva de aprendizagem autorregulada, percepção docente sobre a aprendizagem e métodos educacionais em contabilidade
}

Metacognitive strategy of learning, teaching perception on learning and education methods on accounting

Estrategia metacognitiva de aprendizaje autorregulada, percepción docente sobre aprendizaje y métodos educativos en contabilidad

\section{Thiago Bruno de Jesus Silva}

Mestre em Ciências Contábeis pela Universidade Regional de Blumenau (FURB)

Professor do Curso de Contabilidade na Universidade Federal da Grande Dourados (UFGD)

Endereço: Rodovia Dourados - Itahum, km 12, Zona Rural,

CEP 89012900 - Dourados, MS - Brasil

E-mail: thiagobsilva@ufgd.edu.br

Telefone: (67) 98174-8661

\section{Vania Tanira Biavatti}

Doutora em Ciências Sociais pela Pontifícia Católica de São Paulo (PUC-SP)

Professora no Programa de Pós-Graduação Ciências Contábeis na Universidade Regional de Blumenau (FURB)

Endereço: Rua Antonio da Veiga, 140, Vila Nova.

CEP 89010-971 - Blumenau (UFSC)

E-mail: vania@hprada.com.br

Telefone: (47) 99136-1155

Artigo recebido em 19/12/2016. Revisado por pares em 28/03/2018. Reformulado em 29/05/2018. Recomendado para publicação em 25/02/2019 por Carlos Eduardo Facin Lavarda Editor-Chefe). Publicado em 10/04/2019. 


\section{Resumo}

O objetivo geral desta investigação foi analisar a relação entre o perfil autorregulado de aprendizagem dos discentes aos métodos educacionais de ensino e a percepção docente sobre a aprendizagem no curso de Ciências Contábeis na Universidade Regional de Blumenau (FURB). A investigação utilizou como estratégia de pesquisa o estudo de caso único. A amostra foi composta por 202 discentes e 16 professores do Centro de Ciências Sociais e Aplicadas da instituição, que responderam aos instrumentos de pesquisa. O instrumento de levantamento de dados que foi aplicado aos discentes, sobre o uso das estratégias metacognitivas, foi proposto por Zimerman e Martinez-Ponz (1986) e o aplicado aos docentes foi proposto por Silva (2016). Para análise dos dados, identificaram-se as estratégias de aprendizagem autorregulada, através da estatística descritiva, a análise fatorial e o uso de testes paramétricos de comparação de médias (teste t); a percepção docente sobre a aprendizagem e os métodos de ensino foram alcançados pela análise descritiva dos dados. Por fim, relacionaram-se o perfil do discente quanto à utilização da estratégia metacognitiva de aprendizagem autorregulada, os métodos educacionais de ensino e a percepção docente sobre a aprendizagem. Conclui-se que o ensino tem a consecução de aproximar o conteúdo teórico com o conteúdo prático da contabilidade. Entretanto, ao serem utilizados diferentes métodos de ensino, mesclam-se métodos ativos e passivos de aprendizagem, o que pode ter contribuído no desenvolvimento de nível maior de estratégias metacognitivas de aprendizagem autorregulada. Tem-se como implicação a percepção docente sobre aprendizagem que enfatiza à formação de um profissional com concepções técnicas, o que se limita às regras e desempenho de tarefas rotineiras de contabilidade.

Palavras-chave: Andragogia; Aprendizagem; Metacognição; Métodos educacionais; Educação superior

\section{Abstract}

The present study aimed at analyzing the relationship among the self-regulated learning profile of students, education methods and the professors' perception of learning in the Accounting undergraduate course at the Regional University of Blumenau (FURB), in Brazil. To reach such a goal, the single case study design was employed. The sample consisted of 202 students and 16 professors of the Social and Applied Sciences Center of the institution. The instrument for data collection with students was the one proposed by Zimerman and Martinez-Ponz (1986) while the one with professors was proposed by Silva (2016). For data analysis, we identified the self-regulated learning strategies by means of descriptive statistics, factorial analysis and t-tests for parametric data comparison. As for the professors' perception of learning and education methods, we analyzed the data descriptively. In addition, we related the student's profile with respect to the use of the metacognitive self-regulated learning strategy, education methods and the professors' perception of learning. Results revealed that accounting education has the objective of approximating theory and practice. Nevertheless, when different education methods are employed, active and passive learning methods were combined, which may have contributed to the development of a higher level of metacognitive self-regulated learning strategies. As an implication, the professors' perception about learning emphasized the education of a professional through technical concepts, who is limited to the rules and to the performance of routine accounting tasks.

Keywords: Andragogy; Learning; Metacognition; Educational Methods; Higher education

\section{Resumen}

El objetivo general de esta investigación fue analizar la relación entre el perfil autorregulado del aprendizaje de los discentes a los métodos educativos de enseñanza y la percepción docente sobre el aprendizaje en el curso de Ciencias Contables en la Universidad Regional de 
Blumenau (FURB). La investigación utilizó como estrategia de investigación el estudio de caso único. La muestra fue compuesta por 202 alumnos y 16 profesores del Centro de Ciencias Sociales y Aplicadas de la institución, que respondieron a los instrumentos de investigación. El instrumento de levantamiento de datos que fue aplicado a los discentes sobre el uso de las estrategias metacognitivas, fue propuesto por Zimerman y Martínez-Ponz (1986) y el aplicado a los docentes fue propuesto por Silva (2016). Para el análisis de los datos, se identificaron las estrategias de aprendizaje, a través de la estadística descriptiva, el análisis factorial y el uso de pruebas paramétricas de comparación de promedios (test t); la percepción docente sobre el aprendizaje y los métodos de enseñanza fueron alcanzados por el análisis descriptivo de los datos. Por último, se relacionaron el perfil del alumnado en cuanto a la utilización de la estrategia metacognitiva de aprendizaje autorregulado, los métodos educativos de enseñanza y la percepción docente sobre el aprendizaje. Se concluye que la enseñanza tiene la consecución de aproximar el contenido teórico con el contenido práctico de la contabilidad. Sin embargo, al ser utilizados diferentes métodos de enseñanza, se mezclan métodos activos y pasivos de aprendizaje, lo que puede haber contribuido en el desarrollo de un nivel mayor de estrategias metacognitivas de aprendizaje autorregulado. Se tiene como implicación la percepción docente sobre aprendizaje que enfatiza la formación de un profesional con concepciones técnicas, lo que se limita a las reglas y desempeño de tareas rutinarias de contabilidad.

Palabras clave: Andragogía; Aprendizaje; Metacognición; Métodos educativos; Educación universitaria

\section{Introdução}

Recomendações promovidas pelas autoridades de educação e organismos profissionais de contabilidade do mundo todo apontam para a necessidade de uma formação que conduza os estudantes de Contabilidade a adquirirem habilidades de aprendizagem permanente e pensamento crítico, ou seja, que desenvolvam habilidades metacognitivas. (BECKER, 2013). Contudo, segundo Howieson et al. (2014), a educação em contabilidade ainda enfatiza a importância da formação de um profissional com concepções meramente técnicas, o que limita a formação contábil a regras e desempenho de tarefas rotineiras. Como no mundo atual a mudança é uma constante, além da acumulação do conteúdo técnico, a sociedade exige dos novos profissionais capacidade de lidar com a incerteza e habilidades na resolução dos mais variados problemas. Deste modo, o desenvolvimento acadêmico e profissional de contabilidade, deve, ao contrário do que constaram os autores, enfatizar o "aprender a aprender".

$\mathrm{Na}$ andragogia, a aprendizagem tem uma particularidade centrada na independência e auto-gestão da aprendizagem desde seu príncipio, ao contrário do que ocorre com a pedagogia que toma tal perspectiva como fruto de uma construção de aprendizagem. $\mathrm{O}$ 'aprender a aprender' é, na pedagogia, também uma aprendizagem almejada, entretanto na andragogia assume um status de pressuposto de aprendizagem. Assim, no modelo andragógico, pretendese que os alunos tornem-se, cada vez mais, responsáveis pelo seu próprio aprendizado (HAMZE, 2008). Entendendo a educação adulta como um processo voltado a aprendizagem ao longo da vida, a perspectiva da metacognição e das estratégias de autorregulação da aprendizagem são decisivas para a andragogia na medida em que são importantes no desenvolvimento de habilidade de aprendizagem permanente dos alunos.

Com base na teoria da metacognição, Zimmerman e Martinez-Ponz (1986) desenvolveram a metodologia self-regulated learning (SRL), que apresenta 14 estratégias metacognitivas de autorregulação da aprendizagem, que são: autoavaliação, organização e 
transformação, estabelecimento de objetivos e planejamento, procura de informação, tomada de apontamentos, estrutura ambiental, autoconsequência, repetição e memorização, ajuda externa (professores, pares próximos e especialistas) e revisão (das anotações, de testes e da bibliografia).

Embora Zimmerman (2001), Becker (2011), Moos e Ringdal (2012) e Lombaerts et al. (2008) expliquem que o contexto educacional assume papel particularmente relevante para incentivar níveis maiores de habilidades metacognitivas, a maioria dos estudos anteriores que abordam o tema apenas estabeleceram associação entre as estratégias metacognitivas e o desempenho acadêmico (SCHELEIFER; DULL;, 2009), identificam o papel da intervenção (RAGOSTA, 2010; BECKER, 2011) e analisaram o nível de desenvolvimento de estratégias metacognitivas ao longo do curso (LIMA FILHO ET AL., 2015).

Neste sentido, o contexto educacional, concernente ao método de ensino, orientado por uma escolha circunstanciada na percepção sobre a aprendizagem, desenha um problema de pesquisa, ao que tudo indica, ainda não explorado. Dessa forma, formulou-se o seguinte problema de pesquisa: Como o perfil do discente, no que se refere às estratégias metacognitivas de aprendizagem autorregulada, se relaciona com a percepção e os métodos educacionais de ensino dos docentes do curso de Ciências Contábeis da Universidade Regional de Blumenau (FURB)? Assim, o objetivo dessa investigação foi analisar a relação do perfil autorregulado de aprendizagem dos discentes aos métodos educacionais de ensino e a percepção docente sobre a aprendizagem no curso de Ciências Contábeis na Universidade Regional de Blumenau (FURB).

Nesse contexto, essa pesquisa se justifica na perspectiva de preparo dos alunos para a vida profissional quanto a aprender, manter habilidades e buscar novos conhecimentos, em conformidade com as recomendações dos órgãos internacionais de contabilidade. O estudo apresenta a discussão sobre as estratégias metacognitivas de aprendizagem autorregulada, a percepção docente da aprendizagem e os métodos educacionais. A contribuição prática, os resultados podem servir de discussão para aperfeiçoar as práticas dos professores do ensino superior de contabilidade, por oferecer possíveis explicações da relação entre as estratégias de aprendizagem autorregulada dos estudantes e a percepção docente de aprendizagem. Essa contribuição é importante à luz do reconhecimento de que os discentes, futuros profissionais em contabilidade, necessitam desenvolver habilidades de pensamento crítico, de aprendizagem continuada e a capacidade de fornecer aconselhamento de qualidade para a tomada de decisões, objetivo também instigado pela Comissão para Mudanças na Educação Contábil (Accounting Education Change Commission, 1990), do Instituto Americano de Contadores (American Institute of Certified Public Accountants, 2010).

A esse respeito tem-se observado um número ainda incipiente de estudos (LIMA FILHO et al., 2015). Para Becker (2011), a escassez observada de estudos relacionados a competências de aprendizagem para efeito de aprendizagem ao longo da vida no curso de Ciências Contábeis justifica a realização de novos estudos. Contudo, espera-se contribuir, sobretudo, com reflexões críticas sobre o ensino-aprendizagem desenvolvido com a intenção de armazenar conhecimentos, ainda presente no campo do ensino em Ciências Contábeis, bem como levantar questões sobre o estímulo de habilidades de pensamento dos estudantes, visando torná-los efetivos tomadores de decisões. A construção educacional da aprendizagem autorregulada é alinhada com a aprendizagem ao longo da vida e o conjunto de habilidades que prepara profissionais para o mundo contemporâneo. acionados a competências de aprendizagem para efeito de aprendizagem ao longo da vida no curso de Ciências Contábeis justifica a realização de novos estudos. 


\section{Fundamentação Teórica}

\subsection{Angragogia}

O termo andragogia é definido por Knowles (1970) como a arte e a ciência de ajudar os adultos a aprender, estabelecendo as diferenças com a pedagogia, que aborda o ensino durante o processo de desenvolvimento humano. Enquanto modelo para educação de adultos, caracteriza-se pelo foco no processo de aprendizagem, ao invés da ênfase tradicional no conteúdo (NOFFS; RODRIGUES, 2011). Para Eboli (2004), andragogia é a ciência ou arte de educar pessoas adultas, enquanto que a pedagogia se refere à reflexão sobre a educação de crianças e adolescentes. Para Carvalho et al. (2010), a educação de adultos é um campo diferenciado no âmbito educacional, com características, demandas e possibilidades próprias. Esses alunos trazem consigo uma longa história de conhecimentos acumulados, como reflexões sobre o mundo e as pessoas, e conhecer suas características e necessidades é o ponto de partida para o professor obter sucesso quando considera a aprendizagem significativa.

Como parte do objetivo dessa pesquisa se propõe explicitar a relação entre a opção metodológica, a percepção da aprendizagem do docente, torna-se necessário abalizar que métodos de ensino costumam ser mais utilizados em contabilidade e quais suas implicações nas investigações na área. Método de ensino referem-se aos meios colocados em prática racionalmente para a obtenção de um determinado resultado (SCHMIDT, 2003). Independentemente do método adotado pelo docente, é necessário ter sempre como foco a necessidade do estudante, desenvolver o espírito de reflexão sobre sua própria aprendizagem.

Como recomendações sobre o método de ensino, Schmidt (2003) argumenta que deve evitar o estudo por meio de apontamentos, familiarizar o discente com boas fontes de informações, formar o espírito crítico com base no estudo dos princípios fundamentais de cada disciplina, infundir a todo o ensino os caracteres de instrução e formação, participação ativa do discente na elaboração dos seus conhecimentos, no que tange a raciocinar, interpretar, planejar e investigar.

Drake (2012) argumenta que os métodos educacionais auxiliam os discentes a desenvolverem a aprendizagem ativa e crítica. Neste sentido, Schmidt (2003) recomenda que o ensino universitário deve ensinar a duvidar, levar em consideração opiniões adversas ao invés de se pôr contra elas, não somente ensinar coisas, mas possibilitar meios para aprendê-las e deve dar mais ênfase nos métodos educacionais do que no conteúdo de uma disciplina. DeAquino (2007) defende que o aluno pode desenvolver senso de percepção do que é e do que não é útil através da experiência própria, ou seja, "aprender fazendo", ou ainda, "aprender colocando a mão na massa".

No campo dos métodos educacionais de ensino, alguns estudos se dedicaram a investigar o tema na educação contábil, como são os casos de Andrade (2002), Leal e Cornachione Jr. (2006), Madureira, Succar Jr. e Gomes (2011), Miranda, Leal e Casa Nova (2012), Opdecam e Everaert (2012), Nganga et al. (2013), Leal e Borges (2014), Chiheve (2014).

Os resultados revelam que nem todos os achados de investigações anteriores convergem em relação aos métodos de ensino aplicados em contabilidade. A análise sobre os métodos torna-se relevante ao considerar os modelos de aprendizagem utilizados pelo docente. Contudo, tais estudos não são conclusivos sobre quais são os métodos de ensino mais utilizados e também não os relaciona com o perfil de aprendizagem desenvolvido pelos alunos, o que, portanto, explicita uma lacuna de pesquisa.

Os estudos sugerem que a percepção docente sobre a aprendizagem pode ser voltada tanto para a pedagogia tradicional, com a predominância de abordagem centrada no professor, sobretudo no período inicial do curso, como para uma perspectiva mais andragógica uma vez 
que alguns estudos indicam o uso de metodologias que sugerem uma percepção docente voltada ao incentivo do desenvolvimento de aprendizagens ao longo da vida. A mescla entre métodos de ensino durante o período próximo ao final do curso desvelada pelas pesquisas é uma possibilidade, ao considerar que as matérias gerenciais são do meio ao fim do curso.

A percepção docente sobre a aprendizagem que considere a abordagem centrada no professor tem consequência por não desenvolver discentes preparados a enfrentar o ambiente acadêmico e profissional de contabilidade (KOWLES, 1970). Os próprios órgãos internacionais de contabilidade reconhecem e apontam para se repensar a utilização apenas da abordagem tradicional de ensino e que esta não incentiva que o discente a se tornar aprendiz permanente e com pensamento crítico.

Leal e Cornachione Jr. (2006) explica que o papel do professor na sala de aula não mais como aquele que professa (como sugere a origem etimológica dessa palavra), mas sim como um mediador do desenvolvimento da aprendizagem dos educandos. $\mathrm{O}$ docente em contabilidade, não seria, então, um mero divulgador do conhecimento acumulado por gerações anteriores.

Para Shulman (1987), a educação inicia com a percepção do professor sobre o que está sendo aprendido (conhecimento do assunto) e como vai ser ensinado (metodologia educacional). Segundo Borko (2004), a educação em Ciências Contábeis não é diferente. Zraa et al. (2011) explicam que a tecnologia transformou o papel dos contadores, a partir de uma tarefa técnica para uma mais orientada para o cliente. Desta forma, o ensino e a aprendizagem em contabilidade precisa se ajustar não só em razão do desenvolvimento cognitivo pessoal, mas também em conformidade com os desafios da função.

Para Amoor (2010), o professor além de dominar a disciplina que ensina, entender como os alunos aprendem e saber lidar com os problemas e desafios vivenciados pelos discentes deve ser e capaz de usar métodos educacionais eficazes para todos os alunos. Knowles et al. (2014) explicam que o modelo pedagógico pode contribuir para o perfil de formação do discente. Os autores destacam que a educação dirigida pelo professor, focada no conteúdo, coloca o aluno no papel submisso de seguir instruções. O estudante submetido a uma educação centrada na aprendizagem é mais propenso ao pensamento crítico e aprendizagem ativa (SCHREUDER, 2014).

Postareff e Lindblom (2008) diferenciam as abordagens centradas na aprendizagem e no conteúdo, conforme Quadro 1.

Quadro 1- Tipos de abordagens

\begin{tabular}{|l|l|}
\hline \multicolumn{1}{|c|}{ Abordagem centrada na aprendizagem } & \multicolumn{1}{|c|}{ Abordagem centrada no conteúdo } \\
\hline $\begin{array}{l}\text { Aplicação do conhecimento, ponto de vista em } \\
\text { desenvolvimento, pensamento crítico. }\end{array}$ & $\begin{array}{l}\text { A aprendizagem é sobre memorizar fatos ou lembrar } \\
\text { conteúdo temático. }\end{array}$ \\
\hline $\begin{array}{l}\text { Ensino para atender diferentes alunos. } \\
\text { O professor é consciente de formas diferentes de } \\
\text { aprendizagem e busca melhorar este processo. }\end{array}$ & $\begin{array}{l}\text { Professor transmite conhecimento. } \\
\text { Método educacional escolhido de acordo ao que é } \\
\text { confortável. }\end{array}$ \\
\hline $\begin{array}{l}\text { O professor encoraja o aluno a ser crítico e ativo. } \\
\text { Os alunos aprendem com o Professor e vice-versa. } \\
\text { O professor entende os alunos como participantes } \\
\text { ativos. }\end{array}$ & $\begin{array}{l}\text { O professor tem relação distante com os alunos. } \\
\text { Os alunos aprendem com o professor que transmite o } \\
\text { O professor entende os alunos como destinatários } \\
\text { menos ativos. } \\
\text { O professor é responsável pela aprendizagem. }\end{array}$ \\
\hline $\begin{array}{l}\text { O professor entende que o conhecimento é construído } \\
\text { através da interação em sala. } \\
\begin{array}{l}\text { Os professores utilizam os métodos de ensino } \\
\text { interativo. }\end{array}\end{array}$ & $\begin{array}{l}\text { O professor entende que a interação não constrói o } \\
\text { conhecimento. } \\
\text { Osétodos de ensino interativo. }\end{array}$ \\
\hline
\end{tabular}

Fonte: Postareff e Lindblom (2008). 
$\mathrm{Na}$ abordagem centrada na aprendizagem, destaca-se que o conhecimento é construído por meio da interação, o professor entende os alunos como participantes ativos, encoraja-o a ser crítico. Na abordagem centrada no conteúdo, destaca-se que o professor transmite o conhecimento, é responsável pela aprendizagem e essa é sobre memorizar fatos ou lembrar conteúdo temático.

Schreuder (2014) afirma que os professores devem ter a percepção que o ambiente de aprendizagem deve incentivar os alunos a pensar de forma independente, resolver problemas, analisar e interpretar informações e relacioná-las com o conhecimento prévio e aplicar conhecimento para as circunstâncias necessárias. O ambiente criado pelos professores desempenha papel importante no ensino em contabilidade. De acordo com Ngwenya e Maistry (2012), houve um afastamento das habilidades do contador às dimensões meramente técnicas, e uma aproximação às de comunicação de informações financeiras para tomada de decisões adequadas. Desse modo, Darling-Hammond e McLaughilin (1995) argumentam que no atual clima de mudança em contabilidade, os professores necessitam repensar a sua própria prática.

$\mathrm{O}$ ensino é uma profissão que requer aprendizagem constante. O desenvolvimento profissional contínuo fornece oportunidades para enriquecer o conhecimento e habilidade para proporcionar ensino de qualidade aos estudantes (SCHREUDER, 2014). Amoor (2010) explica que as qualificações afetam a percepção docente sobre a aprendizagem. Villegas-Reimers (2003) explica que o desenvolvimento profissional é baseado no construtivismo, onde os professores estão envolvidos em tarefas de ensino, avaliação, observação e reflexão.

Para Schreuder (2014) e Amoor (2010), a educação continuada e a qualificação são fatores que exercem influência sobre a percepção docente sobre a aprendizagem e que, por consequência, influencia sua prática em sala de aula.

Segundo Chiheve (2014), os professores de contabilidade devem considerar a abordagem centrada na aprendizagem por desafiar o aluno a se tornar autônomo e desenvolver hábitos de aprendizagem ao longo da vida. Contudo, é necessário mesclar a abordagem centrada no conteúdo e na aprendizagem, visto que, segundo esse autor, não é possível usar exclusivamente estratégias de aprendizagem autodirigidas por conta de restrições materiais, tais como recursos de computadores, internet de difícil acesso e etc.

Neste contexto, a percepção docente sobre a aprendizagem influencia o processo de metacognição. Se o docente possui a consciência na orientação do aprendizado ao longo da vida (centrado na aprendizagem), incentiva o discente a pensar sobre como resolver os problemas que se apresentam e com os quais se confrontarão em situações de sua vida acadêmica e profissional contábil.

\subsection{Estratégias Metacognitivas de Aprendizagem Autorregulada}

Segundo Niiemi et al (2014), os alunos necessitam de orientação para o desenvolvimento de suas próprias estratégias metacognitivas que são difíceis para adquirir por conta própria e os professores possuem papel crucial na promoção da aprendizagem autorregulada. Moos e Ringdal (2012) afirmam que a percepção docente sobre a aprendizagem definem seu comportamento e decisões sobre os método de ensino. O professor que percebe o processo de ensino como acumulação de conteúdo e utilizam instrução direta, limita o desenvolvimento da SRL pelos discentes.

O aluno com grau desejável para autorregular sua aprendizagem tende a utilizar 14 categorias de estratégias autorregulatórias, a saber: autoavaliação, organização e transformação, planejamento e elaboração de metas, busca de informações, monitoramento e manutenção das anotações, estruturação do ambiente, autoconsequência, ensaio e memorização, pedido de ajuda aos pares, aos professores, à família, revisão de provas, de anotações e de textos e gerenciamento do tempo (ROSÁRIO, 2004). Além disso, alunos que tendem a apresentar sua 
aprendizagem autorregulada exibem maior rendimento acadêmico e melhores percepções de autoeficácia (ZIMMERMAN, 2001).

Quadro 2 - Estratégias de autorregulação da aprendizagem identificadas por Zimmerman e MartinezPons (1986)

\begin{tabular}{|c|c|c|c|}
\hline \multicolumn{2}{|c|}{ Estratégias: } & Definição: & $\begin{array}{c}\text { Exemplos: (ROSÁRIO, } \\
1999)\end{array}$ \\
\hline 1 & Autoavaliação & $\begin{array}{l}\text { Declarações que indicam as avaliações dos } \\
\text { alunos sobre a qualidade ou progresso do seu } \\
\text { trabalho. }\end{array}$ & $\begin{array}{l}\text { "... verifiquei o meu trabalho } \\
\text { para ter a certeza que estava } \\
\text { bem". }\end{array}$ \\
\hline 2 & $\begin{array}{l}\text { Organização e } \\
\text { transformação }\end{array}$ & $\begin{array}{l}\text { Declarações que indicam as iniciativas dos } \\
\text { alunos para reorganizarem, melhorando-os, os } \\
\text { materiais de aprendizagem. }\end{array}$ & $\begin{array}{l}\text { "... faço sempre um esquema } \\
\text { antes de realizar os relatórios } \\
\text { das experiências de química". }\end{array}$ \\
\hline 3 & $\begin{array}{l}\text { Estabelecimento } \\
\text { de objetivos e } \\
\text { planejamento }\end{array}$ & $\begin{array}{l}\text { Declarações indicando o estabelecimento de } \\
\text { objetivos educativos: planejamento e } \\
\text { conclusão de atividades relacionadas com } \\
\text { esses objetivos. }\end{array}$ & $\begin{array}{l}\text { "... começo a estudar duas } \\
\text { semanas antes do teste e fico } \\
\text { descansada". }\end{array}$ \\
\hline 4 & $\begin{array}{l}\text { Procura de } \\
\text { informação }\end{array}$ & $\begin{array}{l}\text { Declarações indicado os esforços dos alunos } \\
\text { para adquirir informações extra de fontes não } \\
\text { sociais quando enfrentaram uma tarefa } \\
\text { escolar. }\end{array}$ & $\begin{array}{l}\text { “... antes de começar um } \\
\text { trabalho, vou a biblioteca da } \\
\text { escola recolher o máximo de } \\
\text { informações sobre o tema". }\end{array}$ \\
\hline 5 & $\begin{array}{l}\text { Tomada de } \\
\text { apontamentos }\end{array}$ & $\begin{array}{l}\text { Declaração indicando os esforços para } \\
\text { registrar eventos ou resultados }\end{array}$ & $\begin{array}{l}\text { "...nas aulas sorvo o máximo } \\
\text { de apontamentos sobre o que } \\
\text { o professor dá". }\end{array}$ \\
\hline 6 & $\begin{array}{l}\text { Estrutura } \\
\text { ambiental }\end{array}$ & $\begin{array}{l}\text { Declarações indicando esforços para } \\
\text { selecionar ou alterar o ambiente físico ou } \\
\text { psicológico de modo a promover a } \\
\text { aprendizagem. }\end{array}$ & $\begin{array}{l}\text { “... para não me distrair, } \\
\text { isolo-me no quarto" ou "... } \\
\text { para me concentrar no que } \\
\text { estou fazendo, desligo o } \\
\text { som". }\end{array}$ \\
\hline 7 & Autoconsequência & $\begin{array}{l}\text { Declarações indicando a imaginação ou a } \\
\text { concretização de recompensas ou punições } \\
\text { para sucessos ou fracassos escolares. }\end{array}$ & $\begin{array}{l}\text { "... se me der bem no teste, } \\
\text { compro uns chocolates". }\end{array}$ \\
\hline 8 & $\begin{array}{l}\text { Repetição e } \\
\text { memorização }\end{array}$ & $\begin{array}{l}\text { Declarações indicando as iniciativas e os } \\
\text { esforços dos alunos para memorizar o } \\
\text { material. }\end{array}$ & $\begin{array}{l}\text { "... na preparação de um teste } \\
\text { de física, escrevo muitas } \\
\text { vezes a formula, até saber de } \\
\text { cor". }\end{array}$ \\
\hline $9-11$ & $\begin{array}{l}\text { Procura de ajuda } \\
\text { social }\end{array}$ & $\begin{array}{l}\text { Declarações indicando as iniciativas e os } \\
\text { esforços dos alunos para procurarem ajuda dos } \\
\text { pares (9); professores (10); e adultos (11) }\end{array}$ & $\begin{array}{l}\text { "... se tenho dificuldades no } \\
\text { estudo peço ajuda ao meu pai } \\
\text { que é médico" }\end{array}$ \\
\hline $12-14$ & Revisão de dados & $\begin{array}{l}\text { Declarações indicando os esforços-iniciativas } \\
\text { dos alunos para relerem as notas (12); teste } \\
\text { (13); e livros de texto (14) afim de se } \\
\text { prepararem para uma aula ou exercício } \\
\text { escritos. }\end{array}$ & $\begin{array}{l}\text { "... antes dos testes revejo } \\
\text { sempre os resumos da matéria } \\
\text { que fiz" ou "Para me preparar } \\
\text { para um teste resolvo os } \\
\text { enunciados dos que já fiz". }\end{array}$ \\
\hline
\end{tabular}

Fonte: Zimmerman e Martinez-Pons (1986); Rosário, 2001, adaptado.

Tuysuzoglu (2011) argumenta que o perfil do aluno autorregulado é de uma pessoa ativa e construtiva, que, portanto, estabelece metas para o seu aprendizado, acompanhando tal processo e, que busca regular e controlar a sua cognição, motivação e comportamento, guiado e limitado por seus objetivos e características contextuais do ambiente.

Zimmerman (2001), os autorregulados são decididos, estratégicos, persistentes e capazes de avaliar os seus processos, já os não autorregulados não possuem objetivos educacionais definidos, possuindo desta forma, uma maior dependência cognitiva. Destaca-se que o número de utilização de estratégias de aprendizagem é maior para alunos concluintes e que a prática de ensino, como o método educacional, pode promover o comportamento. 
A condição atual desafia a comunidade acadêmica com a expectativa de que os discentes de contabilidade (futuros profissionais) se tornem cada vez mais aptos a enfrentar as transformações e exigências do atual mercado. Esse contexto atende não só a necessidade quanto ao papel do profissional como gestor de informações, mas pode torna-lo indivíduo com maiores chances de realização pessoal.

Segundo Consenza (2001), as universidades necessitam se esforçar para implantar um modelo de ensino para o aluno "aprender a aprender", já que apenas nessa condição os futuros profissionais contábeis possuirão condições de sucesso numa sociedade que está em constante mudança. No entanto, apesar da defesa da aprendizagem ao longo da vida ser incentivada, em muitas salas de aula de contabilidade não se desenvolvem as habilidades metacognitivas. Ainda hoje o desenvolvimento de habilidades metacognitivas pode ser tarefa árdua para os professores de contabilidade que são especialistas em sua disciplina, mas pouco preparados pedagogicamente (BECKER, 2013).

Seja pela modalidade de ensino presencial ou a distância, haja vista a necessidade de formar profissionais com condições de aprender a aprender. Nesse sentido, para Moos e Ringdal (2012), a dependência de aula expositiva, instrução direta, pode limitar oportunidades para que os alunos desenvolvam habilidades de aprendizagem autorregulada. Chiheve (2014) recomendam que os professores de contabilidade considerem a abordagem centrada na aprendizagem por desafiar o aluno a se tornar autônomos e desenvolver hábito de aprendizagem ao longo da vida.

A percepção docente sobre a aprendizagem desempenha papel importante na consecução de desenvolvimento metacognitivo. Nessa condição, o professor de contabilidade que possui percepção voltada a abordagem centrada no aluno incentiva a aprendizagem autorregulada no lugar da aprendizagem mecânica de memorização de informações, visto que os métodos de ensino direcionam a responsabilidade de aprender para o aluno (SCHREUDER, 2014).

No campo das estratégias metacognitivas de aprendizagem autorregulada, poucos estudos se dedicaram a investigar o tema na educação contábil, como são os casos de Schleifer e Dull (2009), Byrne e Flood (2009), Becker (2011) e Lima Filho et al. (2015).

A convergência entre tais pesquisas, está no fato de que a maioria dos estudos investigaram a associação entre as estratégias metacognitivas de aprendizagem autorregulada e o desempenho acadêmico. Estes estudos concluíram que alunos de contabilidade que utilizam maior número de estratégias de aprendizagem possuem desempenho superior.

O estudo do Becker (2011) distingue-se desses por analisar o papel da intervenção (ambiente de treinamento) para aumentar o número de estratégias de aprendizagem. A autora considera a instrução das estratégias de aprendizagem como parte do processo educacional. No entanto, a literatura sobre andragogia ressalta que atividades rotuladas como treinamento colocam o discente adulto de volta a experiência escolar com postura de dependência cognitiva. A literatura também destaca que a percepção e os métodos educacionais são fatores que podem auxiliar ou comprometer o desenvolvimento de postura crítica para adaptação aos contextos de mudanças acadêmicas e profissionais da contabilidade, auxiliar a tomada de decisões em ambientes de incertezas, aprender a conteúdos desconhecidos e obter sucesso acadêmico e profissional por possuir o controle do seu processo de aprendizagem, conforme mencionam Dull e Scheleifer (2009) e Becker (2011).

Para auxiliar o discente, o professor deve adotar abordagem voltada à aprendizagem. Ou seja, o docente, consciente de formas diferentes de aprendizagem, encoraja o aluno a ser crítico e ativo. O conhecimento é construído por meio da interação e que usa métodos de ensino interativos e experimentais.

Embora os estudos anteriores abordem a estratégia de aprendizagem autorregulada, não consideraram o contexto educativo, como a influência da percepção docente da aprendizagem. 
As evidências, como as apontadas pelo estudo do Lima Filho et al. (2015) de que o aluno ingressante e o aluno formando não apresentam diferença em relação ao número de uso de estratégia de aprendizagem, estimularam a realização dessa investigação, visto que a literatura sobre metacognição afirma que a percepção docente deve incetivar níveis maiores de habilidades metacognitivas.

\section{Procedimentos Metodológicos}

O estudo adotou abordagem qualitativa e utiliza como estratégia de pesquisa o estudo de caso único, com escopo descritivo, cuja finalidade é responder à questão "Como o perfil do discente, no que se refere à estratégia metacognitiva de aprendizagem autorregulada, se relaciona com a percepção sobre a aprendizagem pelos docentes do curso de Ciências Contábeis da Universidade Regional de Blumenau (FURB)?”.

Ao considerar que processo de avaliação do Exame Nacional de Desempenho dos Estudantes (ENADE) pondera as competências, habilidades e a evolução do discente durante o desenvolvimento do curso, adotou-se a maior nota entre as instituições de Santa Catarina no curso de Ciências Contábeis como critério para seleção do caso. Dessa forma, a universidade selecionada para o estudo de caso foi a Universidade Regional de Blumenau - FURB. Os sujeitos participantes da investigação foram os 202 discentes que responderam o instrumento voltado a estratégias de metacognição da aprendizagem autorregulada, 16 docentes que responderam o instrumento que aborda a percepção da aprendizagem docente sobre a aprendizagem. Destaca-se que a acessibilidade aos dados necessários para elaboração desta investigação, também, foi importante para se definir na escolha do caso.

A fim de garantir a qualidade do estudo de caso, quanto a validade do constructo, adotaram-se múltiplas fontes de coleta de dados, quais sejam, a análise de documentos, os quais, por sua vez, possibilitaram a triangulação de dados.

Para alcançar o objetivo geral, o estudo estrutura três objetivos específicos. Assim, o primeiro objetivo específico (A), identificar as estratégias metacognitivas de aprendizagem autorregulada na evolução dos discentes durante o curso, utilizou-se questionário com questões fechadas. Em relação ao segundo objetivo específico (B), investigar a percepção docente sobre a aprendizagem, também se utilizou questionário questões fechadas e uma aberta somando esse à análise nos planos de ensino (para B1). Desta forma, para atender ao objetivo do estudo, analisar a relação do perfil autorregulado de aprendizagem dos discentes à percepção docente sobre a aprendizagem no curso de Ciências Contábeis na Universidade Regional de Blumenau (FURB), utilizou-se os dados levantados a partir dos instrumentos utilizados para alcance dos objetivos específicos A e B.

No Quadro 3 apresenta-se o constructo para identificar as estratégias metacognitivas de aprendizagem autorregulada na evolução dos discentes durante o curso, sua dimensão, variáveis, mensuração e estudos anteriores (A). Utilizou-se o instrumento elaborado por Zimmerman e Martinez-Ponz (1986) que inclui dez afirmações relativas ao uso das estratégias, conforme no Apêndice A. A seleção desse instrumento deu-se a partir da análise de frequência de sua utilização na literatura, como Becker (2011; 2013), Lima Filho et al (2015) e Silva (2016).

Os estudos anteriores evidenciaram, em sua maioria, que o nível de utilização de estratégias autorregulada de aprendizagem entre os discentes na fase final é maior quando se comparado com os discentes em fase inicial do curso.

O instrumento de pesquisa aplicado aos discente foi formado por dois blocos com 13 questões em seu total. O primeiro bloco foi composto de três questões concernentes ao semestre em curso, gênero, idade. O segundo bloco foi formado por dez buscou captar o uso das 
estratégias de aprendizagem. No instrumento, o discente deveria atribuir uma única resposta entre 1 (nunca) e 7 (sempre), conforme os estudos.

Quadro 3 - Constructo sobre as estratégias metacognitivas de aprendizagem autorregulação, objetivo específico A

\begin{tabular}{|c|c|c|c|c|}
\hline Objetivo específico & Dimensão & Variáveis & Mensuração & Estudos anteriores \\
\hline $\begin{array}{l}\text { (a) Identificar as } \\
\text { estratégias } \\
\text { metacognitivas } \\
\text { aprendizagem } \\
\text { autorregulada } \\
\text { evolução dos discentes } \\
\text { durante o curso. }\end{array}$ & $\begin{array}{l}\text { Estratégias } \\
\text { metacognitivas } \\
\text { de aprendizagem } \\
\text { autorregulada }\end{array}$ & $\begin{array}{l}\text { 1-Autoavaliação; } \\
2 \text { - Organização e } \\
\text { transformação; } \\
3 \text {-Estabelecimento } \\
\text { de objetivos e } \\
\text { planejamento; } \\
4 \text { - Procura de } \\
\text { informação; } \\
5 \text { - Tomada de } \\
\text { apontamentos; } \\
6 \text { - Estrutura de } \\
\text { ambiental; } \\
7 \\
\text { Autoconsequência; } \\
8 \text { - Repetição e } \\
\text { memorização; } \\
9 \text { - Procura de ajuda } \\
\text { social; } \\
10 \text { - Revisão de } \\
\text { dados }\end{array}$ & 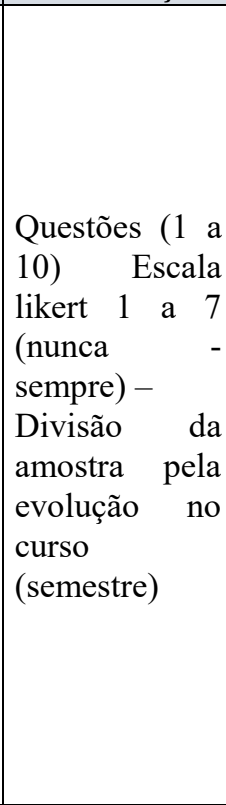 & $\begin{array}{l}\text { Boruchovitch } \\
\text { Rosário (2001); } \\
\text { Zimmermann } \\
\text { Schunk (2005); Lombaerts } \\
\text { et al., (2008); Byrne e Flood } \\
\text { (2009); Schleifer e Dull } \\
\text { (2009); Martin e Dowson, } \\
\text { (2009); Becker (2011; } \\
\text { 2013), Lima Filho et al. } \\
(2015)\end{array}$ \\
\hline
\end{tabular}

Fonte: Autoria própria

No Quadro 4 apresenta-se para investigar os métodos educacionais de ensino relatados e a percepção docente sobre a aprendizagem que foi dividido entre os métodos educacionais registrados e relatados (B1) e percepção docente sobre a aprendizagem (B2). Neste quadro, além da dimensão, são apresentadas as variáveis, sua forma de mensuração e os autores de referência.

O instrumento de pesquisa aplicado aos docentes foi construído por Silva (2016). Para os métodos de ensino, a mensuração foi através da identificação dos métodos registrados nos planos de ensino. Na percepção docente sobre a aprendizagem, utilizou-se três questões a partir do instrumento de pesquisa. As duas questões de múltipla escolha destacam as justificativas de escolha dos métodos de ensino e a questão aberta aborda a percepção dos docentes sobre a influência da metodologia de ensino adotada na formação (perfil) do futuro profissional de contabilidade.

Após examinar a relação das estratégias metacognitivas de aprendizagem autorregulada na evolução dos discentes no curso e investigar a percepção docente sobre a aprendizagem e os métodos educacionais de ensino utilizados nas disciplinas pelos docentes, foi estabelecido suas relações em atendimento ao objetivo geral relacionar o perfil de aprendizagem dos alunos à percepção e aos métodos educacionais de ensino relatados durante a evolução do discente no curso de Ciências Contábeis e, por conseguinte, à questão problema do estudo.

A coleta de dados foi durante o curso de formação continuada que ocorreu no dia 16 de fevereiro de 2016 e também na plataforma google docs no período entre os dias 19 de fevereiro a 07 de março de 2016. O instrumento de pesquisa sobre as estratégias metacognitivas de aprendizagem autorregulada foi aplicado aos discentes em sala de aula no período entre os dias 10 e 25 de novembro de 2015. Os planos de ensino foram coletados através do site da instituição no período entre os dias 26 de dezembro de 2015 a 03 de janeiro de 2016 . A coleta deu-se por meio do sistema interno de gerenciamento dos planos de ensino, de livre acesso aos alunos 
regularmente matriculados na instituição. No sistema encontrou-se 64 disciplinas, no entanto não estavam publicados 27 planos de ensino. Dessa forma, analisou-se 37 planos de ensino.

Quadro 4 - Constructo sobre os métodos educacionais de ensino e a percepção docente sobre a aprendizagem, objetivo específico $B$

\begin{tabular}{|c|c|c|c|c|}
\hline Objetivo específico & Dimensão & Variáveis & Mensuração & Autores \\
\hline \multirow{2}{*}{$\begin{array}{l}\text { (B) Investigar os } \\
\text { métodos educacionais } \\
\text { de ensino relatados e a } \\
\text { percepção docente } \\
\text { sobre a aprendizagem }\end{array}$} & $\begin{array}{l}\text { (B1) Métodos } \\
\text { educacionais } \\
\text { registrados e } \\
\text { relatados }\end{array}$ & $\begin{array}{c}\text { Aula expositiva; } \\
\text { Discussões em grupo; } \\
\text { Resoluções de exercícios; } \\
\text { Leitura e estudo dirigido; } \\
\text { Seminário; Aulas práticas; } \\
\text { Estudo de caso; Discussão } \\
\text { com toda a classe; } \\
\text { Palestras; Visitas técnicas; } \\
\text { Simulações; Aulas com } \\
\text { vídeos; Ensino com } \\
\text { pesquisa; Dinâmica em } \\
\text { grupo; Mesa redonda; PBL } \\
\text { (Aprendizagem Baseada } \\
\text { em Problema); Jogos; } \\
\text { Diálogos sucessivos; } \\
\text { Escritório modelo de } \\
\text { contabilidade }\end{array}$ & $\begin{array}{c}\text { Identificação } \\
\text { nas questões } \\
6 \text { e } 8 \text { de } \\
\text { múltipla } \\
\text { escolha }\end{array}$ & $\begin{array}{c}\text { Kowles (1970); } \\
\text { DeAquino (2007); } \\
\text { Hamze (2008); Moos e } \\
\text { Ringdal (2012); } \\
\text { Schreuder (2014); } \\
\text { Howieson et al. (2014); } \\
\text { Leal e Borges (2014); } \\
\text { Knwoles et al. (2014) }\end{array}$ \\
\hline & $\begin{array}{c}\text { (B2) Percepção } \\
\text { Docentes Sobre } \\
\text { a } \\
\text { Aprendizagem }\end{array}$ & $\begin{array}{l}\text { Abordagem centrada no } \\
\text { conteúdo } \\
\text { Abordagem centrada na } \\
\text { aprendizagem }\end{array}$ & $\begin{array}{l}\text { Identificação } \\
\text { nos planos de } \\
\text { ensino } \\
\text { Questões } 7 \text { e } \\
9 \text { de múltipla } \\
\text { escolha } \\
\text { Questão } 10 \\
\text { aberta }\end{array}$ & $\begin{array}{l}\text { Leal e Cornachione Jr. } \\
\text { (2006); DeAquino } \\
\text { (2007); Moreira e } \\
\text { Oliveira (2012); Becker } \\
\text { (2011); Madureira, } \\
\text { Succar Jr., Gomes } \\
\text { (2011); Drake (2012) } \\
\text {;Miranda, Leal, Casa } \\
\text { Nova (2012); Opdecam } \\
\text { e Everaert (2012); } \\
\text { Nganga et al. (2013); } \\
\text { Leal e Borges } \\
\text { (2014);Chiheve (2014); } \\
\text { Borges e Leal (2015) }\end{array}$ \\
\hline
\end{tabular}

Fonte: Autoria própria

Segundo Yin (2010), com a triangulação dos dados, os problemas potenciais de validade do constructo também podem ser abordados, porque as múltiplas fontes de evidência proporcionam, em essência, várias avaliações do mesmo fenômeno. Para Denzin e Lincol (2006), a triangulação dos dados, ou o emprego de métodos múltiplos, reflete uma tentativa de assegurar uma interpretação em profundidade dos fenômenos em questão. No estudo utilizaram-se questionários aplicados aos discentes e professores e análise dos planos de ensino, no que concerne aos métodos registrados.

Para identificar as estratégias na evolução dos discentes no curso, inicialmente, identificou-se o nível de utilização das estratégias com o auxílio da estatística descritiva. Em seguida, foi aplicada a análise fatorial com o intuito de resumir e reduzir os dados e os testes paramétricos de comparação de médias (teste t) para apontar a existência de diferenças significativas na utilização das estratégias entre discentes no estágio inicial (até o $5^{\circ}$ semestre) e o estágio final (a partir do $6^{\circ}$ semestre) do curso.

No entanto, a utilização de técnicas estatísticas não significa que o estudo seja quantitativo. A pesquisa é qualitativa especialmente por ser um estudo de caso, embora utilizouse, de modo auxiliar, dessas técnicas para consecução dos objetivos específicos. 
Nessa etapa, para os métodos educacionais de ensino registrados e relatados pelos professores, identificaram-se aqueles registrados nos planos de ensino nas disciplinas analisadas e os relatados nas questões 6 e 8 de múltipla escolha do instrumento de pesquisa com a estatística descritiva. Quanto a percepção sobre a aprendizagem, aplicou-se a estatística descritiva nas questões 7 e 9 e na questão 10 aplicou-se a análise descritiva.

A seguir a análise foi realizada considerando os resultados encontrados as duas primeiras etapas e, que, desta forma, permitiu inferir resultados fundamentado nas perspectivas teorias da andragogia e da metacognição.

\section{Análise e Discussão dos Resultados}

\subsection{Estratégias metacognitivas de aprendizagem autorregulada}

Primeiramente, caracterizou-se os discentes participantes da pesquisa, conforme Tabela 1. Em seguida, aplicou-se a estatística descritiva para identificar as estratégias de aprendizagem autorregulada utilizadas pelos discentes participantes. Também se examinou a relação dessas estratégias na evolução dos discentes no curso com o auxílio da Análise Fatorial e os testes paramétricos de comparação de médias.

Tabela 1 - Características da amostra dos discentes

\begin{tabular}{|c|c|c|c|c|c|c|c|c|c|}
\hline $\begin{array}{l}\text { IES } \\
\mathrm{Fi} \\
\mathrm{Fi} \%\end{array}$ & FURB & & & & & & & & $\begin{array}{r}\text { Total } \\
202 \\
100,00\end{array}$ \\
\hline Gênero & Feminino & Masculino & & & & & & & \\
\hline $\mathrm{Fi}$ & 136 & 66 & & & & & & & \\
\hline $\mathrm{Fi} \%$ & 67,3 & 32,7 & & & & & & & \\
\hline Idade & Até 20 & 21 a 25 & 26 a 30 & 31 a 35 & Acin & le 36 & & & \\
\hline $\mathrm{Fi}$ & 100 & 68 & 20 & 8 & 6 & & & & \\
\hline $\mathrm{Fi} \%$ & 49,50 & 33,66 & 9,90 & 3,96 & 2,97 & & & & \\
\hline Semestre & 1 & 2 & 3 & 4 & 5 & 6 & 7 & 8 & \\
\hline $\mathrm{Fi}$ & 21 & 44 & 26 & 30 & 22 & 27 & 14 & 18 & \\
\hline $\mathrm{Fi} \%$ & 10,4 & 21,8 & 12,9 & 14,9 & 10,9 & 13,4 & 6,9 & 8,4 & \\
\hline
\end{tabular}

Fonte: Dados da pesquisa.

No Tabela 1 destaca que $67,3 \%$ da amostra foi formada por estudantes do gênero feminino. Ao analisar a faixa etária dos discentes, a maioria possui até 20 anos $(49,50 \%)$, $33,66 \%$ entre 21 e 25 anos, $9,90 \%$ com 26 a 30 anos 3,96\% entre 31 a 35 anos e apenas $2,97 \%$ acima de 36 anos. Em relação ao semestre letivo, a maioria $(21,8 \%)$ se encontra no segundo semestre e $6,9 \%$ se encontram no sétimo período. Destaca-se que a maioria $(49,50 \%)$ dos discentes possuem até 20 anos.

$\mathrm{Na}$ Tabela 2, identificou-se as estratégias metacognitivas de aprendizagem autorregulada utilizadas pelos estudantes para enfrentar suas tarefas acadêmicas. Vale ressaltar que nas duas últimas colunas apresentam uma totalização das frequências, para respostas menores que quatro e maiores que quatro, sendo um ponto médio entre 1 e 7 .

Como resultado, verificou-se que as estratégias megacomitivas que os discentes usam preferencialmente para enfrentar suas tarefas acadêmicas foram E10 (revisão de dados), E1 (autoavaliação), E6 (estrutura ambiental) e E9 (ajuda externa). Estas estão concentradas entre as três fases da autorregulação da aprendizagem, fase de planejamento, de execução e autorreflexão. Destaca-se que a maioria das estratégias metacognitivas está acima do ponto médio a exceção da E7 (estratégia de autoconsequência). 
Pode-se inferir que os discentes utilizam de forma significativa as estratégias metacognitivas do modelo de autorregulação de Zimmerman e Martinez-Ponz (1986). As estratégias mais empregadas são caracterizadas na segunda e terceira fase. A segunda fase (execução e controle) tem o propósito de fazer cumprir os objetivos traçados na primeira fase. É exigido nessa etapa auto monitoração através do uso de estratégias de aprendizado e do controle da atenção. A terceira fase de autorreflexão e autorreação (avaliação) envolve o julgamento, autoavaliação e atribuições de causa sobre os objetivos estabelecidos na primeira fase (estabelecimento de objetivo e planejamento).

Tabela 2 - Identificar as estratégias de aprendizagem autorregulada dos discentes

\begin{tabular}{|c|c|c|c|c|c|c|c|c|c|c|c|}
\hline \multirow{3}{*}{\multicolumn{2}{|c|}{ Estratégia }} & \multicolumn{7}{|c|}{ Respostas } & \multirow{3}{*}{ Total } & \multirow{3}{*}{$\begin{array}{c}\text { Menor } \\
\text { que } 4\end{array}$} & \multirow{3}{*}{$\begin{array}{c}\text { Maior } \\
\text { que } 4 \\
\end{array}$} \\
\hline & & \multirow{2}{*}{$\frac{1}{\text { Nunca }}$} & \multirow[t]{2}{*}{2} & \multirow[t]{2}{*}{3} & \multirow[t]{2}{*}{4} & \multirow[t]{2}{*}{5} & \multirow[t]{2}{*}{6} & \multirow{2}{*}{$\begin{array}{c}7 \\
\text { Sempre }\end{array}$} & & & \\
\hline & & & & & & & & & & & \\
\hline \multirow{2}{*}{ E1 } & Total & 4 & 3 & 6 & 27 & 61 & 55 & 46 & 202 & 13 & 162 \\
\hline & $\%$ & 2,0 & 1,5 & 3,0 & 13,4 & 30,2 & 27,2 & 22,8 & 100,00 & 6,44 & 80,20 \\
\hline \multirow{2}{*}{ E2 } & Total & 12 & 13 & 23 & 41 & 54 & 35 & 24 & 202 & 48 & 113 \\
\hline & $\%$ & 5,9 & 6,4 & 11,4 & 20,3 & 26,7 & 17,3 & 11,9 & 100,00 & 23,76 & 55,94 \\
\hline \multirow{2}{*}{ E3 } & Total & 35 & 43 & 32 & 42 & 29 & 8 & 13 & 202 & 110 & 50 \\
\hline & $\%$ & 17,3 & 21,3 & 15,8 & 20,8 & 14,4 & 4,0 & 6,4 & 100,00 & 54,45 & 24,75 \\
\hline \multirow{2}{*}{ E4 } & Total & 5 & 18 & 15 & 33 & 27 & 38 & 66 & 202 & 38 & 131 \\
\hline & $\%$ & 2,5 & 8,9 & 7,4 & 16,3 & 13,4 & 18,8 & 32,7 & 100,00 & 18,82 & 64,85 \\
\hline \multirow{2}{*}{ E5 } & Total & 3 & 17 & 21 & 32 & 46 & 44 & 39 & 202 & 41 & 126 \\
\hline & $\%$ & 1,5 & 8,4 & 10,4 & 15,8 & 22,8 & 21,8 & 19,3 & 100,00 & 20,30 & 62,37 \\
\hline \multirow{2}{*}{ E6 } & Total & 2 & 7 & 20 & 24 & 38 & 43 & 68 & 202 & 29 & 149 \\
\hline & $\%$ & 1,0 & 3,5 & 9,9 & 11,9 & 18,8 & 21,3 & 33,7 & 100,00 & 14,35 & 73,76 \\
\hline \multirow{2}{*}{ E7 } & Total & 94 & 23 & 21 & 24 & 20 & 10 & 10 & 202 & 138 & 40 \\
\hline & $\%$ & 46,5 & 11,4 & 10,4 & 11,9 & 9,9 & 5,0 & 5,0 & 100,00 & 68,31 & 19,80 \\
\hline \multirow{2}{*}{ E8 } & Total & 5 & 15 & 20 & 30 & 52 & 44 & 36 & 202 & 40 & 132 \\
\hline & $\%$ & 2,5 & 7,4 & 9,9 & 14,9 & 25,7 & 21,8 & 17,8 & 100,00 & 19,80 & 65,34 \\
\hline \multirow{2}{*}{ E9 } & Total & & 7 & 16 & 13 & 27 & 55 & 84 & 202 & 23 & 136 \\
\hline & $\%$ & & 3,5 & 7,9 & 6,4 & 13,4 & 27,2 & 41,6 & 100,00 & 11,38 & 67,32 \\
\hline \multirow{2}{*}{ E10 } & Total & 1 & 3 & 7 & 25 & 36 & 49 & 81 & 202 & 11 & 166 \\
\hline & $\%$ & 0,5 & 1,5 & 3,5 & 12,4 & 17,8 & 24,3 & 40,1 & 100,00 & 5,5 & 82,17 \\
\hline
\end{tabular}

Legenda: E1 - estratégia de autoavaliaçao; E2 - estratégia de organização e transformação; E3 - estratégia de estabelecimento de objetivos e planejamento; E4 - estratégia de procura de informação; E5 - estratégia de tomada de apontamentos; E6 - estratégia de estrutura ambiental; E7 - estratégia autoconsequência; E8 estratégia de repetição e memorização; E9 - estratégia de procura de ajuda social; E10 - estratégia de revisão de dados.

Fonte: dados da pesquisa.

Em contrapartida, as estratégias menos utilizadas pelos discentes para enfrentar suas rotinas acadêmicas foram E7 (autoconsequência) e E3 (estabelecimentos de objetivos e planejamento). Estas estão divididas entre a fase de planejamento e autorreflexão, respectivamente.

Os resultados foram convergentes ao estudo do Lima Filho et al. (2015) que investigaram quais estratégias metacognitivas os discentes utilizavam em suas rotinas acadêmicas. Os achados também apontam que os discentes não empregam o estabelecimento de objetivos e planejamento. Zimmerman (2001) explica que esta fase é afetada pelo conjunto de crenças de autoeficácia (aspecto motivacional) que o aluno possui, como a sua percepção e expectativa de realização das tarefas. Para Corno (1989), o emprego das estratégias facilita o processo de aprendizagem. [

Desta forma, ao considerar que o processo de autorregulação se concretiza de forma cíclica, caso algum discente da amostra deste estudo não empregue a estratégia de estabelecimento de objetivos e planejamento as demais fases (execução/controle e 
autorreflexão) poderão ser comprometidas. Segundo Demetriou (2000) a participação ativa do estudante exige consciência dos objetivos a serem alcançados, reconhecimento das demandas da ação a se alcançar, separação e estabelecimento os recursos internos e externos para a execução da ação, avaliação do nível de realização e alteração os procedimentos utilizados se o resultado não for o previsto.

Após identificar quais as estratégias de aprendizagem autorregulada utilizadas pelos estudantes, buscou verificar essas estratégias a partir do estágio (semestre) do estudante no curso de acordo com o objetivo específico A. Para tanto, utilizou-se, a análise fatorial com o intuito de resumir e reduzir dados (HAIR et al., 1998), conforme descrito na Tabela 3.

Tabela 3 - Autovalores para as estratégias de aprendizagem (SRL)

\begin{tabular}{c|ccc|ccc}
\hline \multirow{2}{*}{ Componente } & \multicolumn{7}{|c|}{ Autovalor Inicial } & \multicolumn{3}{c}{ Somas extraídas dos carregamentos Quadráticos } \\
\cline { 2 - 7 } & Total & \% da Variância & \% Acumulado & Total & \% da Variância & \% Acumulado \\
\hline 1 & 3,002 & 30,021 & 30,021 & 3,002 & 30,021 & 30,021 \\
\hline 2 & 1,241 & 12,408 & 42,429 & 1,241 & 12,408 & 42,429 \\
\hline 3 & 1,035 & 10,352 & 52,781 & 1,035 & 10,352 & \\
\hline 4 & 0,969 & 9,694 & 62,781 & & & \\
\hline 5 & 0,906 & 9,059 & 71,535 & & \\
\hline 6 & 0,674 & 6,735 & 78,270 & & \\
\hline 7 & 0,619 & 6,187 & 84,456 & & & \\
\hline 8 & 0,571 & 5,710 & 90,166 & & & \\
\hline 9 & 0,543 & 5,435 & 95,601 & & & \\
\hline 10 & 0,440 & 4,399 & 100,000 & & & \\
\hline
\end{tabular}

Fonte: Dados da pesquisa.

Como se pode verificar, foram gerados 3 fatores com percentual de informação para o modelo de $30,02 \%$ para o primeiro fator, $12,40 \%$ para o segundo fator e 10,35 para o terceiro fator. Utilizou-se o método de rotação oblíqua Promax para analisar os coeficientes de correlação. Esta rotação disponibiliza duas matrizes e uma matriz de estrutura, além da matriz fatorial, que delineiam padrões de intercorrelações entre as variáveis oblíquas. As cargas fatoriais determinam os padrões e o grau de envolvimento de cada variável com os padrões. $\mathrm{Na}$ Pattern Matrix pelas cargas fatoriais em cada padrão, a matriz de estrutura informa a extensão da correlação das variáveis com os padrões de forma generalizada (CATELL, 1966).

Catell (1996) e Menezes (2006) explicam que a determinação do fator chega ao final quando se verifica a afinidade dos itens com os fatores que expurga os constructos do modelo quando o valor absoluto da carga fatorial principal do item for menor que 0,32 na existência de cargas fatoriais similares em dois ou mais fatores for inferior a 0,10 e também o fator deve ser formado por dois ou mais itens. Ao considerar estes critérios, na Tabela 4 descreve a sua utilização e os coeficientes de correlações com o método de Pattern Matrix.

Tabela 4 - Análise dos coeficientes de correlações com o método de Pattern Matrix

\begin{tabular}{ccccccccccc}
\hline Dimensão & $E 1$ & $E 2$ & $E 3$ & $E 4$ & E5 & E6 & E7 & E8 & E9 & E10 \\
\hline 1 & $\mathbf{0 , 6 0 7}$ & 0,471 & $\mathbf{0 , 5 9 6}$ & $\mathbf{0 , 6 0 1}$ & $\mathbf{0 , 7 1 3}$ & $\mathbf{0 , 4 2 4}$ & 0,168 & $\mathbf{0 , 5 0 3}$ & $\mathbf{0 , 5 4 4}$ & $\mathbf{0 , 6 5 5}$ \\
2 & 0442 & $\mathbf{0 , 5 3 1}$ & 0,272 & $-0,480$ & $-0,098$ & -0467 & 0,399 & 0,056 & $-0,209$ & $-0,161$ \\
3 & $-0,287$ & $-0,297$ & 0,209 & 0,130 & 0,148 & 0,214 & $\mathbf{0 , 7 8 5}$ & 0,078 & $-0,313$ & $-0,131$ \\
\hline
\end{tabular}

Fonte: Dados da pesquisa.

Com a utilização dos critérios propostos por Hair et al. (1998), o item E2 (transformação e organização) na dimensão 2 e o item E7 (autoconsequência) foram excluídos ao considerar que apenas um fator não deve ser formado por dois ou mais itens. Desta forma, a dimensão, obtida pela análise conjunta, foi formada pelos itens E1 (autoavaliação), E3 (estabelecimento de objetivos e planejamento), E4 (procura de informação), E5 (tomada de 
apontamentos), E6 (estrutura ambiental), E8 (repetição e memorização), E9 (ajuda externa) e E10 (revisão).

Para a realização dessa pesquisa, a dimensão foi intitulada de Estratégias de Aprendizagem Autorregulada e foi validada de acordo com os procedimentos apresentados por Netemeyer et al. (2003) e resumido na Tabela 5 com as verificações de dimensionalidade, confiabilidade e convergência da análise fatorial.

O valor do KMO foi considerado desejável e o teste de Esferidade de Bartlett foi de baixo nível de significância. O Alfa de Conbrach $(0,762)$ também foi considerado desejável e todos os Coeficientes de Pearson foram positivos e significativos.

Na Tabela 5 apresenta-se a consecução do primeiro objetivo específico de examinar a relação das estratégias metacognitivas de aprendizagem autorregulada na evolução dos discentes no curso. Para tanto, a amostra foi dividida em dois grupos de acordo com o estágio (semestre) do curso (até o quinto semestre e a partir do sexto semestre) considerando os estudos anteriores, Rosário (2001), Sperling (2004), Lombaerts et al., (2009) e Schleifer e Dull (2009) e Lima Filho et al. (2015).

Tabela 5 - Testes de Igualdade de Média Dimensão Estratégias de Aprendizagem Autorregulada (SRL)

\begin{tabular}{|c|c|c|c|c|c|c|c|c|c|}
\hline \multirow[b]{2}{*}{ Estágio no curso } & \multirow[b]{2}{*}{$\mathrm{N}$} & \multirow[b]{2}{*}{ Média } & \multirow[b]{2}{*}{$\begin{array}{l}\text { Desvio } \\
\text { Padrão }\end{array}$} & \multirow[b]{2}{*}{$\begin{array}{l}\text { Erro Padrão } \\
\text { da média }\end{array}$} & \multicolumn{2}{|c|}{ Teste de Levene } & \multicolumn{3}{|c|}{ T teste } \\
\hline & & & & & $\mathrm{F}$ & Sig & $\mathrm{t}$ & $\begin{array}{l}\text { Graus de } \\
\text { liberdade }\end{array}$ & $\begin{array}{c}\text { Sig } \\
\text { bi }\end{array}$ \\
\hline Até o $5^{\circ}$ semestre & 121 & 4,7603 & 1,69325 & 0.15393 & 5171 & 0024 & 1,592 & 200 & $\begin{array}{c}0.00 \\
4 \\
\end{array}$ \\
\hline $\begin{array}{l}\text { A partir do } 6^{\circ} \\
\text { semestre }\end{array}$ & 81 & 5,1235 & 1,41759 & 0.15751 & $5,1 / 1$ & $0,0<4$ & 1,649 & 190,152 & $\begin{array}{c}0.00 \\
4\end{array}$ \\
\hline
\end{tabular}

Fonte: dados da pesquisa.

Os resultados apontam a existência de diferenças significativas na utilização das estratégias metacognitivas de acordo ao estágio do curso com níveis de significância de 0,04. De modo geral os dados permitem inferir que houve aumento do grau de utilização das estratégias metacognitivas pelos discentes, embora a média entre discentes no estágio inicial e final não possuir diferença considerável.

Contudo, pode-se conclui que os discentes tendem a se apropriar das estratégias metacognitivas a medida que progridem no curso (semestre). O resultado foi semelhante aos estudos do Rosário (2001), Sperling (2004), Lombaerts et al., (2009) e Schleifer e Dull (2009). No entanto foi de encontro ao estudo do Lima Filho et al. (2015). Similar ao Sperling (2004) e Schleifer e Dull (2009), a pesquisa demonstrou que os alunos do curso de contabilidade em estágio final possuem nível superior de utilização de estratégias metacognitivas que os alunos em estágio inicial. Para Schleifer e Dull (2009), ao longo da escala educativa o discente se adapta as demandas acadêmicas e atributos metacognitivos. Sperling (2004) explica que os atributos metacognitivos possuem relações com o uso das estratégias de aprendizagem de forma eficaz.

Como o nível de utilização das estratégias analisados ao longo dos semestres difere significativamente, o perfil dos discentes em período de formação foi ao encontro as recomendações promovidas pelas autoridades de educação e organismos profissionais de contabilidade. Desta forma, por meio do emprego de estratégias metacognitivas, os indivíduos instrumentalizaram-se melhor para navegar em ambientes instáveis, muitas vezes criados por contextos dinâmicos (MOENIKIA; ABTIN, 2006). Desse modo, a aprendizagem autorregulada envolve uma abordagem de autoconsciência para realização acadêmica, os quais são essenciais para uma carreira bem-sucedida em contabilidade.

Lombaerts et al. (2009) explicam que as práticas de ensino deverão incentivar a aprendizagem autorregulada. Lima Filho et al. (2015) não encontraram diferença significativa 
na utilização das estratégias metacognitivas de acordo com o estágio do curso. Para os autores (2015), tem-se a importância do ensino ser voltado para uma maior independência dos estudantes, não só nas instituições analisadas, mas em todas as Instituições de Ensino Superior (IES) que oferecem o curso de contabilidade.

Neste contexto, considerando as explicações do Lombaerts et al.(2009), os resultados do estudo do Lima Filho et al. (2015) e com base nesses dados parciais dessa pesquisa, podese inferir que as atitudes independentes e pensamento crítico pode ser promovidas no curso analisado, uma vez que o aluno ingressante e o aluno formando apresentam diferença significativa sobre o nível de de utilização de estratégia cognitiva.

\subsection{Os métodos educacionais de ensino registrados e relatados e a percepção docente sobre aprendizagem}

\subsubsection{Métodos Educacionais}

De forma inicial, foi analisado os métodos educacionais registrados pelos professores nos planos de e ensino e depois os métodos de ensino relatados nas respostas as questões 6 e 8 do instrumento de pesquisa. Destaca-se a importância dessa investigação por permitir comparar os métodos educacionais registrados nos planos de ensino com os métodos educacionais relatados como utilizados e que proporcionam melhor aprendizagem. Com a análise torna-se possível inferir se os métodos de ensino podem incentivar níveis maiores de habilidades metacognitivas.

$\mathrm{Na}$ Tabela 6 evidencia-se os métodos educacionais de ensino mais mencionados nos planos de ensino das disciplinas.

Tabela 6 - Estatística descritiva dos métodos educacionais nos planos de ensino

\begin{tabular}{l|c}
\hline \multicolumn{1}{c|}{ Métodos Educacionais } & $\%$ \\
\hline Aula expositiva & 29,63 \\
\hline Estudo de caso & 19,44 \\
\hline Dinâmica em grupo & 12,96 \\
\hline Resoluções de exercícios & 10,19 \\
\hline Aula prática & 6,48 \\
\hline Estudo dirigido & 8,34 \\
\hline Discussão em grupo & 3,70 \\
\hline Seminário & 3,70 \\
\hline Discussão com toda classe & 2,78 \\
\hline Jogos de empresas & 0,93 \\
\hline Palestras & 0,93 \\
\hline Simulações & 0,93 \\
\hline Total & 100,00 \\
\hline
\end{tabular}

Fonte: Dados da Pesquisa

Os resultados, conforme Tabela 6, indicam que o método mais utilizado registrado nos planos de ensino é a aula expositiva, estudo de caso, dinâmica em grupo e resoluções de exercícios. Já os métodos menos utilizados foram simulações, palestras, discussão com toda a classe, seminário, discussão em grupo, estudo dirigido e aula prática.

O método de ensino aula expositiva possui predominância quando comparado aos outros métodos utilizados pelos professores descritos no plano de ensino. Todavia, pode-se dizer também que há uma mescla com outros métodos quando se considera que a aula expositiva obteve $29,63 \%$, o segundo método (estudo de caso) obteve $19,44 \%$ e o terceiro método (dinâmica em grupo) 12, 96\%. 
Tais resultados são convergentes com os estudos do Leal e Borges (2014) e Chiheve (2014), nos quais os resultados apontam que o método mais utilizado é a aula expositiva/tradicional. Leal e Borges (2014) também concluíram, de forma semelhante a este estudo, que os métodos com maior indicação pelos docentes registrados no plano de ensino foram aula expositiva, estudo de caso e aplicação/resoluções de exercícios.

Os resultados foram semelhantes ao estudo do Leal e Cornachione Jr. (2006) em relação a mescla de métodos educacionais em detrimento a aula expositiva. Leal e Cornachione Jr. (2006) concluíram que, quando ocorre mescla de métodos, os discentes demonstraram maior nível de desenvolvimento de competências de formação. No entanto, conforme as explicações do Chiheve (2014), o método de aula expositiva limita o desenvolvimento de aprendizagem ao longo da vida, e os docentes devem usar estratégias que incentivem os alunos a estudar de forma independente.

Alguns métodos que possibilitam ao aluno posicionamento crítico-reflexivo, como visitas técnicas, mesa redonda e PBL (Aprendizagem Baseada em Problema), entre outros, não foram listados nos planos de ensino. Black (2012), Cootzee e Schmulian (2012) afirmam que há movimentação no sentido de introduzir metodologias focadas no aluno como estratégia que possibilitam à formação de profissionais críticos.

Na Tabela 7 apresenta-se os métodos educacionais registrados nos planos de ensino das disciplinas por semestre.

Tabela 7 - Métodos educacionais registrados nos planos de ensino por semestre

\begin{tabular}{|c|c|c|c|c|c|c|c|c|c|}
\hline \multirow{2}{*}{ Métodos Educacionais } & & \multicolumn{8}{|c|}{ Semestre } \\
\hline & & $\mathbf{1}^{\mathbf{0}}$ & $2^{\circ}$ & $3^{\circ}$ & $4^{\circ}$ & $\mathbf{5}^{\circ}$ & $6^{\mathbf{0}}$ & $7^{0}$ & $8^{\circ}$ \\
\hline \multirow{2}{*}{ Aula expositiva } & Total & 4,00 & 4,00 & 5,00 & 5,00 & 4,00 & 4,00 & 3,00 & 3,00 \\
\hline & $\%$ & 28,57 & 33,33 & 33,33 & 35,71 & 23,53 & 30,77 & 23,08 & 30,00 \\
\hline \multirow{2}{*}{ Estudo de caso } & Total & 0 & 2,00 & 3,00 & 3,00 & 5,00 & 2,00 & 1,00 & 5,00 \\
\hline & $\%$ & 0 & 16,67 & 20,00 & 21,43 & 29,41 & 15,38 & 7,69 & 50,00 \\
\hline \multirow{2}{*}{ Dinâmica em grupo } & Total & 2,00 & 2,00 & 2,00 & 1,00 & 4,00 & 3,00 & 0 & 0 \\
\hline & $\%$ & 14,29 & 16,67 & 13,33 & 7,14 & 23,53 & 23,08 & 0 & 0 \\
\hline \multirow{2}{*}{ Resoluções de exercícios } & Total & 2,00 & 2,00 & 3,00 & 1,00 & 2,00 & 0 & 1,00 & 0 \\
\hline & $\%$ & 14,29 & 16,67 & 20,00 & 7,14 & 11,76 & 0 & 7,69 & 0 \\
\hline \multirow{2}{*}{ Aula prática } & Total & 1,00 & 0 & 1,00 & 3,00 & 0 & 1,00 & 1,00 & 0 \\
\hline & $\%$ & 7,14 & 0 & 6,67 & 21,43 & 0 & 7,69 & 7,69 & 0 \\
\hline \multirow{2}{*}{ Estudo dirigido } & Total & 2,00 & 2,00 & 0 & 0 & 2,00 & 0 & 2,00 & 0 \\
\hline & $\%$ & 14,29 & 0,17 & 0 & 0 & 0,12 & 0 & 0,15 & 0 \\
\hline \multirow{2}{*}{ Discussão em grupo } & Total & 0 & 0 & 0 & 0 & 0 & 2,00 & 1,00 & 1,00 \\
\hline & $\%$ & 0 & 0 & 0 & 0 & 0 & 15,38 & 7,69 & 10,00 \\
\hline \multirow{2}{*}{ Seminário } & Total & 1,00 & 0 & 0 & 0 & 0 & 0 & 2,00 & 1,00 \\
\hline & $\%$ & 7,14 & 0 & 0 & 0 & 0 & 0 & 15,38 & 10,00 \\
\hline \multirow{2}{*}{ Discussão com toda classe } & Total & 1,00 & & 1,00 & 1,00 & & & & \\
\hline & $\%$ & 7,14 & & 6,67 & 7,14 & & & & \\
\hline \multirow{2}{*}{ Jogos de empresas } & Total & & & & & & & 1,00 & \\
\hline & $\%$ & & & & & & & 7,69 & \\
\hline \multirow{2}{*}{ Leitura de textos } & Total & & & & & & & 1,00 & \\
\hline & $\%$ & & & & & & & 7,69 & \\
\hline \multirow{2}{*}{ Palestras } & Total & 1,00 & & & & & & & \\
\hline & $\%$ & 7,14 & & & & & & & \\
\hline \multirow{2}{*}{ Simulações } & Total & & & & & & 1,00 & & \\
\hline & $\%$ & & & & & & 7,69 & & \\
\hline \multirow{2}{*}{ Total } & Total & 14,00 & 12,00 & 15,00 & 14,00 & 17,00 & 13,00 & 13,00 & 10,00 \\
\hline & $\%$ & 100,00 & 100,00 & 100,00 & 100,00 & 100,00 & 100,00 & 100,00 & 100,00 \\
\hline
\end{tabular}

Fonte: dados da pesquisa.

Verifica-se que a aula expositiva foi utilizada durante todos os semestres do curso, seguido do estudo de caso presente em sete semestres, dinâmica em grupo, resoluções de 
exercícios e aula prática em cinco semestres, estudo dirigido em 4 semestres, discussão em grupo, seminário e discussão com toda classe em três semestres e jogos de empresas, leitura de textos, palestras e simulações com apenas uma presença. Os resultados são convergentes ao estudo do Andrade (2002) sobre os métodos mais utilizados durante a fase introdutória. O autor (2002) destaca que independente da turma ocorre a utilização predominante da aula expositiva.

Quando se analisa cada semestre, percebe-se que o primeiro e o sétimo foram os que apresentaram mais variedade de métodos. O oitavo, o segundo e o quinto foram os que menos variedade de métodos utilizaram. Destaca-se que, em média, os demais semestres utilizaram entre seis e sete métodos de ensino. Buckhaults e Fisher (2011) explicam que a utilização de diversas técnicas pode promover o uso de ferramentas diferenciadas para desenvolver habilidades de análise, tomada de decisão e comunicação, pouco usuais nas metodologias de ensino convencionais.

Ao analisar os métodos de forma individual, percebe-se a involução da aula expositiva durante a evolução da escala educativa pelos discentes, a evolução do estudo de caso, dinâmica de grupo e o uso dos métodos simulações, jogos de empresas, aula prática, discussão em grupo durante a fase final do curso. Para Romanowky e Beuren (2002), quando a participação dos alunos se limita a realização de exercícios não favorece a constituição de um pensamento crítico, autônomo e criativo. Destaca-se que a involução da aula expositiva, o crescimento do uso do estudo de caso e o experimento de mais métodos de ensino ocorreram nas matérias da área gerencial no curso de contabilidade. Desta forma, os resultados são convergentes ao estudo elaborado por Nganga et al., (2013) e Borges e Leal (2015).

Opdecam e Everaert (2012) explicam que o investimento de tempo em uma metodologia de ensino que privilegiasse o aprendizado em equipe, tendo no professor a figura de facilitador, pode aumentar os níveis de aprendizado e desempenho dos estudantes. Assim, segundo DeAquino (2007), o aluno pode desenvolver senso de percepção do que é e do que não é útil através da experiência própria, ou seja, "aprender fazendo", ou ainda, "aprender colocando a mão na massa”.

Após a análise dos métodos de ensino registrados nos planos de ensino, na Tabela 8 apresentam os métodos relatados como utilizados pelos professores.

Tabela 8 - Métodos educacionais utilizados

\begin{tabular}{l|c|c}
\hline \multicolumn{1}{c|}{ Métodos Educacionais } & Fi & Fi\% \\
\hline Aula expositiva & 16 & 100,00 \\
\hline Discussões em grupo & 13 & 81,30 \\
\hline Resoluções de exercícios & 13 & 81,30 \\
\hline Leitura e estudo dirigido & 12 & 75,00 \\
\hline Seminário & 11 & 68,80 \\
\hline Aulas práticas & 11 & 68,80 \\
\hline Método do caso/estudo de caso & 10 & 62,50 \\
\hline Discussão com toda a classe & 7 & 43,80 \\
\hline Palestras & 6 & 37,50 \\
\hline Visitas técnicas/excursões & 4 & 25,00 \\
\hline Simulações & 4 & 25,00 \\
\hline Aulas com vídeo & 4 & 25,00 \\
\hline Ensino com pesquisa & 4 & 25,00 \\
\hline Dinâmica em grupo & 3 & 18,80 \\
\hline Mesa redonda & 2 & 12,50 \\
\hline PBL (Aprendizagem Baseada em Problema) & 2 & 12,50 \\
\hline Jogos & 1 & 6,30 \\
\hline Diálogos sucessivos & 1 & 6,30 \\
\hline Escritório modelo de contabilidade & 1 & 6,30 \\
\hline Total de respondentes & $\mathbf{1 6}$ & $\mathbf{1 0 0 , 0 0}$ \\
\hline Fonte: dados da pesquisa. & &
\end{tabular}


De acordo aos dados da Tabela 8, os métodos mais utilizados pelos professores são aula expositiva, discussões em grupo, resoluções de exercícios, leitura e estudo dirigido e seminário e aulas práticas. Já os métodos menos utilizados foram mesa redonda, PBL, jogos, diálogos sucessivos e escritório modelo de contabilidade.

O método de ensino aula expositiva é predominante, visto que todos os professores mencionaram utilizá-lo. Os resultados permitem concluir que os docentes também utilizam outros métodos, como discussões em grupo, resoluções de exercícios e leitura e estudo dirigido. Neste sentido, os demais métodos de ensino podem ser usados de forma complementar às aulas expositivas, como a resolução de exercício (SOARES, 2008).

No entanto, destaca-se, também, a pouca utilização do método de ensino escritório modelo de contabilidade. Os resultados corroboram o estudo do Stanley e Marsden (2012) que acentua a resistência para a utilização de metodologias ativas no ensino de contabilidade. Para Knowles (2014), alunos se tornam pronto para aprender quando experimentam a necessidade de saber algo que se conecta às suas situações de vida.

Os professores unanimemente utilizam a aula expositiva de forma predominante e os demais métodos de ensino, conforme deduz-se dos dados de pesquisa, podem ser usados de forma complementar. Assim, apesar da predominância da aula expositiva, os resultados indicam mescla entre as abordagens, uma vez que, ainda que de forma auxiliar, além da aula expositiva utilizam também outros métodos durante as aulas.

Na próxima Tabela 9 apresenta-se os dados concernentes aos métodos educacionais descritos pelos professores como que possibilitam melhor aprendizagem

Tabela 9 - Métodos educacionais que possibilitam melhor aprendizagem

\begin{tabular}{l|c|c}
\hline \multicolumn{1}{c|}{ Métodos Educacionais } & Fi & Fi\% \\
\hline Aulas práticas & 14 & 87,50 \\
\hline Aula expositiva & 12 & 75,00 \\
\hline Método do caso/estudo de caso & 11 & 68,80 \\
\hline Resoluções de exercícios & 11 & 68,80 \\
\hline Discussões em grupo & 9 & 56,30 \\
\hline Seminário & 8 & 50,00 \\
\hline Leitura/estudo dirigido & 7 & 43,80 \\
\hline Discussão com toda classe & 7 & 43,80 \\
\hline Visitas técnicas & 6 & 37,50 \\
\hline Palestras & 5 & 31,30 \\
\hline Escritório modelo de contabilidade & 5 & 31,30 \\
\hline Simulações & 4 & 25,00 \\
\hline Mesa redonda & 4 & 25,00 \\
\hline Aula com vídeo & 3 & 18,80 \\
\hline PBL (Aprendizagem Baseada em Problema) & 2 & 12,50 \\
\hline Total de respondentes & $\mathbf{1 6}$ & $\mathbf{1 0 0 , 0 0}$ \\
\hline Font dados da pesquisa & &
\end{tabular}

Fonte: dados da pesquisa.

Os métodos de ensino aula prática, aula expositiva, estudo de caso e resoluções de exercícios são os que possibilitam melhor aprendizagem segundo os professores participantes da pesquisa. Excetuando o método tradicional (aula expositiva), os demais são voltados a explorar a experiência e que favorecem a interação em sala de aula. Ao comparar a aula expositiva com os demais métodos, os professores compreendem que esta não é mais adequada que a aula prática. Ressalta-se, também, que os resultados foram equilibrados, sem predominância de apenas um método.

Em contraste aos métodos listados, pois possibilitam melhor aprendizagem, os métodos mesa redonda, aula com vídeo e PBL foram os menos utilizados. Autores como Black (2012), Coetzee e Schmulian (2012) apontam para a necessidade de mudanças nas práticas de 
ensino em contabilidade, entretanto as investigações demonstram baixo uso de metodologias ativas em contabilidade, conforme os resultados por Pereira, Niyama e Freire (2012) e Stanley e Marsden (2012).

Cabe, então, ao professor refletir sobre os métodos de ensino que contribuem para a formação profissional limitados aos aspectos técnicos ou de profissionais críticos com aptidão reflexiva nos assuntos de contabilidade. Como por exemplo, o método PBL que é caracterizado pelo uso de problemas do mundo real e que, por sua vez, aproxima o aluno da realidade encontrada nas empresas. Como implicância de não o utilizar, o professor não encoraja os alunos a desenvolverem pensamento crítico e habilidades de solução de problemas e não adquirem conhecimento sobre os conceitos essenciais da área em questão (LOMBAERTS et al., 2009).

Ao comparar os resultados dos métodos registrados nos planos de ensino com os relatados como utilizados e os métodos que proporcionam melhor aprendizado, nota-se predominância da aula expositiva, exceto os métodos relatados como possibilitam melhor aprendizado. Alguns métodos ativos não foram listados, sobretudo os que se conectam com situações reais. Estes achados são característicos da pedagogia tradicional uma vez que a abordagem está centrada no professor, embora os professores demonstrem possuir discernimento que os métodos ativos serem melhor para o aprendizado,

Ainda na análise comparativa, conclui-se que os professores usam métodos variados. Como os resultados dos planos de ensino evidenciaram que a aula expositiva decresce enquanto os métodos ativos aumentam no momento em que as disciplinas gerenciais iniciam, mas que não há predominância de um único em específico, pode-se inferir que há mescla das abordagens centradas na aprendizagem e no conteúdo.

No entanto, os métodos listados como os que propiciam melhor aprendizado não são os mesmos relatados como os utilizados em sala de aula e registrados no plano de ensino. Alguns fatores, como receio ou não podem utilizar métodos interativos, podem explicar esse gap entre as metodologias teoricamente discutidas e aquelas que efetivamente são utilizadas, conforme apresentado por Postareff e Lindblom (2008).

Nesse interim, após investigar os métodos registrados nos planos de ensino e relatados pelos professores, apresenta-se, na Tabela 10, a justificativa para escolha dos métodos de ensino.

Tabela 10 - Justificativa para escolha dos métodos de ensino

\begin{tabular}{c|c|c}
\hline Justificativa para a escolha & Método que possibilita melhor aprendizagem & Método que utiliza \\
\hline Facilita o aprendizado & $87,5 \%$ & $87,5 \%$ \\
\hline Aproxima a teoria da prática & $87,5 \%$ & $93,8 \%$ \\
\hline Proporciona interação & $75,0 \%$ & $62,5 \%$ \\
\hline Desperta o interesse & $75,0 \%$ & $75,0 \%$ \\
\hline Auxilia na fixação do conteúdo & $56,3 \%$ & $68,8 \%$ \\
\hline Possibilita a troca de experiência & $56,3 \%$ & $56,3 \%$ \\
\hline Estimula novas pesquisas & $37,5 \%$ & $31,3 \%$ \\
\hline Estimula a criatividade & $31,3 \%$ & $25,0 \%$ \\
\hline São as técnicas mais usadas & $31,3 \%$ & $31,3 \%$ \\
\hline Total de respondentes & $\mathbf{1 6}$ & $\mathbf{1 0 0 , 0 \%}$ \\
\hline
\end{tabular}

Fonte: Dados da Pesquisa

Verifica-se que, na percepção dos respondentes, as razões que consideram para a escolha dos métodos como os melhores são as que: facilitam o aprendizado, aproximam a teoria da prática, proporcionam interação e desperta o interesse. De acordo com os resultados dos métodos que os docentes utilizam: aproximam a teoria da prática, facilitam o aprendizado, despertam o interesse e auxiliam na fixação do conteúdo. 
De acordo aos resultados, os métodos de ensino e justificativas dos docentes para escolha como os melhores métodos de ensino são convergentes à abordagem centrada na aprendizagem. Postareff e Lindblom (2008) explicam que os professores que entendem o aluno como participante ativo, compreendem que o conhecimento é construído através da interação em sala, que os alunos aprendem com o professor e vice-versa.

Nesse sentido, conclui-se que os docentes entendem que os métodos ativos são os mais indicados para utilização em sala de aula. Tais métodos são considerados voltados a proporcionar aumento dos níveis de utilização de estratégias metacognitivas e pensamento crítico.

Contudo, quanto aos resultados para os métodos de ensino utilizados pelos professores e suas justificativas de uso, pode-se inferir que há mescla entre as abordagens na aprendizagem e no conteúdo. Sobre a aprendizagem centrada no conteúdo ou no professor, Postareff e Lindblom (2008) explicam que o professor tem receio ou não pode utilizar métodos de ensino interativos, tem relação distante com os alunos, transmite o conhecimento e a aprendizagem é sobre memorizar fatos ou lembrar conteúdo temático. Já na aprendizagem centrada na aprendizagem, percebe que os docentes instigam os alunos a buscar respostas, encoraja o aluno a ser crítico e ativo.

Entretanto, ao considerar os métodos de ensino registrados e relatados, os resultados sugerem que a percepção docente sobre a aprendizagem pode ser voltada para a pedagogia tradicional ao considerar que os métodos relatados como os melhores não são os mesmos relatados como utilizados, além da predominância da aula expositiva. Nessa condição, a mescla entre os métodos de ensino pode ter o objetivo em aproximar a teoria com a prática visando à formação técnica em contabilidade e não no sentido de preparar o profissional com habilidade de pensamento crítico e autônomo.

\subsubsection{Percepção Docente Sobre a Aprendizagem}

Entre os 16 professores pertencentes a amostra do estudo, a maioria possui entre 40 a 45 anos ( 5 respondentes), sendo 4 respondentes com idade entre 45 e 50 anos, 2 com idade entre 35 a 40 anos, e, apenas um professor em cada intervalo, entre 25 a 30 anos, 30 a 35 anos, 50 a 55 anos e 60 a 65 anos. Verifica-se que a maioria possui mestrado acadêmico, sendo 7 professores concluído e um com o mestrado em fase de andamento, 4 professores com doutorado, 3 professores com o doutorado em andamento e um professor com o pós-doutorado em andamento. Quanto ao tempo de experiência, a maioria possui de 10 a 15 anos de experiência com 4 professores. Vale ressaltar que não há predominância entre as idades de experiência, com tempo de docência que varia até 25 anos.

Percebe-se que não há predominância entre a forma de dedicação a docência, sendo que 8 exercem de forma de forma exclusiva e 8 exercem de forma concomitante com outra atividade profissional. Quando se questionou sobre a participação em curso e/ou outras atividades de aprimoramento da formação docente, verifica-se que a maioria dos professores participa em curso e/ou outras atividades de aprimoramento da formação docente. Apenas 2 respondentes informaram que raramente participam de atividades de aprimoramento de sua formação.

De acordo aos resultados, verifica-se existência de diversidade nas características dos docentes e que, dessa forma, pode justificar uma possível mescla entre as abordagens no conteúdo e de formas de aprendizagem.

Após a caracterização dos professores da instituição, apresentam-se a percepção da metodologia de ensino adotada pelo professor na formação (perfil) do futuro profissional de contabilidade. 
Estratégia metacognitiva de aprendizagem autorregulada, percepção docente sobre a aprendizagem e métodos educacionais em contabilidade

Quadro 5 - Percepção da influência da metodologia de ensino adotada pelo professor na formação (perfil) do futuro profissional de contabilidade

\begin{tabular}{|c|c|}
\hline Respondente 1 & $\begin{array}{l}\text { "A influência metodológica contribui para a assimilação e junção do conteúdo teórico com } \\
\text { a prática profissional." }\end{array}$ \\
\hline Respondente 2 & $\begin{array}{l}\text { "[...] é preciso fazer uma mescla de métodos de ensino, capacitando o aluno adquirir } \\
\text { conhecimentos mais completos acerta da contabilidade [...] criação dessa nova visão pode } \\
\text { iniciar pelas dinâmicas de ensino aprendizagem utilizadas pelos professores" }\end{array}$ \\
\hline Respondente 3 & $\begin{array}{l}\text { "A metodologia permite um processo de ensino/aprendizagem mais estruturado e } \\
\text { consistente." }\end{array}$ \\
\hline Respondente 4 & $\begin{array}{l}\text { "A metodologia é capaz de estimular o aluno em superar desafios na aprendizagem. Alguns } \\
\text { métodos são capazes de despertar interesse em aprofundar-se. As novas gerações precisam } \\
\text { de estímulos visuais, de variação no modo de transmitir conhecimento, gostam de aulas } \\
\text { participativas aonde eles não são meros receptores." }\end{array}$ \\
\hline Respondente 5 & $\begin{array}{l}\text { "[...] o professor deve aplicar metodologias de ensino diferentes }[\ldots] \text { o importante é o } \\
\text { professor saber julgar qual metodologia é mais adequada para aquele conteúdo, ou até } \\
\text { mesmo, para determinada turma" }\end{array}$ \\
\hline Respon & "[...] uma boa metodologia é que pode despertar realmente o interesse do aluno" \\
\hline Respondente 7 & $\begin{array}{l}\text { "A metodologia utilizada tem toda a influência positiva quando aplicada o método correto } \\
\text { para a disciplina específica. Deve-se analisar método x disciplina x curso, esses devem } \\
\text { caminhar juntos para que tenhamos bons 'resultados'." }\end{array}$ \\
\hline Respondente 8 & $\begin{array}{l}\text { "A metodologia de ensino adotada propicia a participação interativa dos acadêmicos, além } \\
\text { disso possibilita unir a teoria com a prática." }\end{array}$ \\
\hline Respondente 9 & $\begin{array}{l}\text { "É o ponto principal para atingir as metas propostas. Um bom preparo mais uma boa técnica } \\
\text { é igual a uma boa aula." }\end{array}$ \\
\hline Respondente 10 & $\begin{array}{l}\text { "A metodologia adequada proporciona uma maior dinâmica no processo de } \\
\text { ensino/aprendizagem, com participação do estudante e docente." }\end{array}$ \\
\hline Respondente 11 & "Imprescindível." " \\
\hline Respondente 12 & $\begin{array}{l}\text { "Processo direto e permite dinâmica diferenciada, que promove a comunicação, dinâmica } \\
\text { na transformação do indivíduo e aprimoramento profissional." }\end{array}$ \\
\hline pondente 13 & "Ferramenta 'chave' para atingir o objetivo." \\
\hline Respondente 14 & $\begin{array}{l}\text { "[...] O escritório modelo pode ser uma aproximação maior com o mundo profissional real } \\
{[\ldots] \text { há diferentes barreiras para sua implantação e manutenção [...] O estágio poderia ser }} \\
\text { uma excelente oportunidade, mas os escritórios não aderem" }\end{array}$ \\
\hline Respondente 15 & $\begin{array}{l}\text { "A metodologia de ensino utilizada pode favorecer ou dificultar a aprendizagem. Não há } \\
\text { uma única metodologia que pode ser considerada a mais adequada. Um conjunto de } \\
\text { metodologias combinadas e aplicadas adequadamente, podem favorecer as condições para } \\
\text { aprendizagem dos diferentes conteúdos abordados no ensino de contabilidade." }\end{array}$ \\
\hline Respondente 16 & $\begin{array}{l}\text { "Acredito que a metodologia pode estimular o aluno a gostar mais de um tema ou disciplina } \\
\text { em detrimento de outra. Tal influência pode, inclusive, estimular o aluno a seguir campos } \\
\text { específicos de atuação ou despertar algum." }\end{array}$ \\
\hline
\end{tabular}

Fonte: Dados da Pesquisa

No Quadro 5 pode ser observado a percepção sobre a influência da metodologia de ensino adotada pelo professor na formação (perfil) do futuro profissional de contabilidade, sendo que para 3 respondentes, a percepção de aproximação maior com o mundo profissional, participação ativa do discente é evidente que esse aspecto, por conceito, está atrelada a teoria andragógica, ou seja, adultos estão prontos para aprender as coisas que precisam saber e serem capazes de realizar a fim de aplicar isso eficientemente nas situações reais de suas vidas (KNOWLES, 2014). Dentre os respondentes com discursos convergentes à abordagem centrada na aprendizagem, o respondente 4 destacou "o método é responsável por contribuir com dinamismo, inovação, e alguns deles desafiam o aluno a sair de seu comodismo atribuindo a eles a corresponsabilidade em construir o conhecimento".

Em outro grupo formado por 7 respondentes, a percepção dos professores é atrelada a pedagogia tradicional, com discurso que aborda a transmissão do conhecimento e conteúdo. 
Dentre os respondentes, o respondente 5 destacou "Dependendo do conteúdo, cada metodologia tem sua particularidade [...] a resolução do conteúdo pode ser mais adequada, enquanto para outra turma, o seminário produz melhores resultados". Nesta visão, os alunos são sujeitos centrados e os professores percebem a aprendizagem como a aquisição de conteúdo da matéria (KNOWLES et al., 1998).

Verificam-se respostas entre a abordagem centrada no conteúdo e abordagem centrada na aprendizagem. Estas percepções podem explicar a mescla adotada na utilização e a justificativa de escolha mencionada pelos docentes para os métodos de ensino. Como destaca o respondente 2 "[...]é preciso mesclar aspectos práticos com estudos de caso e resolução de exercícios, com leituras reflexivas e seminários [...] será formado um profissional de contabilidade que compreende seus aspectos técnicos, mas também tenha desenvoltura para discorrer sobre diversos assuntos".

A mescla entre as abordagens no conteúdo e na aprendizagem pode ser explicada pelas características do docente, como o tempo de docência, formação e idade distintas. Contudo, pode-se inferir que os professores demonstram percepções da aprendizagem com mais características da pedagogia tradicional do que da andragógica. A percepção desses docentes sugere não ter intenção explicita em tornar o discente aprendiz autônomo e com habilidade de pensamento crítico e sim voltado à preparação técnica da profissão contábil, conforme o respondente 1 afirma "A influência metodológica contribui para a assimilação e junção do conteúdo teórico com a prática profissional.". Nesse sentido, os docentes utilizam múltiplos métodos de ensino para aproximar a teoria com a prática profissional sem o discernimento que a sua prática pode desenvolver habilidades metacognitivas nos discentes.

Embora autores como Ngwenya e Maitry (2012), Scheuder (2014) afirmam que houve afastamento das atribuições da profissão contábil e que os professores devem ter a percepção que o ambiente de aprendizagem deve incentivar os alunos a desenvolver o pensamento crítico, percebe-se que a percepção dos docentes é centrada no conteúdo, ou seja, voltada a "transmissão do conhecimento", "assimilação do conteúdo", "adquirir conhecimento".

Considerando os resultados e estimulado pelas afirmações do Amoor (2010) e Schreuder (2014) que a experiência dos professores afeta a percepção docente sobre a aprendizagem, no Quadro 6, apresentam-se as percepções docentes sobre a influência da metodologia de ensino adotada na formação segregada pelo tempo de experiência em sala de aula com o intuito de obter melhor distinção entre as percepções.

Em análise no Quadro 6, pode ser observado que o tempo de experiência não afetou a percepção docente sobre a aprendizagem. Um dos respondentes entre 15 a 20 anos de experiência, por exemplo, afirma que "o importante é o professor julgar qual metodologia é mais adequada para aquele conteúdo", outro respondente com o tempo entre 10 e 15 anos de experiência explica que "Um conjunto de metodologias combinadas e aplicadas adequadamente, podem favorecer as condições para aprendizagem dos diferentes conteúdos", já para outro entre 5 e 10 anos, "As novas gerações precisam de estímulos visuais, de variação no modo de transmitir conhecimento".

A maioria se reporta a influência do método de ensino com a preocupação em transmissão, assimilação e acumulação do conteúdo e busca junção da teoria com a prática técnica contábil. Os respondentes com o tempo de experiência entre 0 a 5 anos possuem, também, a percepção voltada ao conteúdo, conforme um dos respondentes afirma: "A influência metodológica contribui para a assimilação e junção do conteúdo teórico com a prática profissional.". 


\begin{tabular}{|c|c|}
\hline \multirow{3}{*}{$\begin{array}{l}0 \text { a } 5 \\
\text { anos }\end{array}$} & $\begin{array}{l}\text { "A influência metodológica contribui para a assimilação e junção do conteúdo teórico com a prática } \\
\text { profissional." }\end{array}$ \\
\hline & $\begin{array}{l}\text { "[...] é preciso fazer uma mescla de métodos de ensino, capacitando o aluno adquirir conhecimentos } \\
\text { mais completos acerta da contabilidade [...] a criação dessa nova visão pode iniciar pelas dinâmicas } \\
\text { de ensino aprendizagem utilizadas pelos professores." }\end{array}$ \\
\hline & $\begin{array}{l}\text { "A metodologia de ensino adotada propicia a participação interativa dos acadêmicos, além disso } \\
\text { possibilita unir a teoria com a prática." }\end{array}$ \\
\hline \multirow{3}{*}{$\begin{array}{l}5 \text { a10 } \\
\text { anos }\end{array}$} & $\begin{array}{l}\text { "A metodologia é capaz de estimular o aluno em superar desafios na aprendizagem. Alguns métodos } \\
\text { são capazes de despertar interesse em aprofundar-se com leituras e pesquisas fora da instituição de } \\
\text { ensino. As novas gerações precisam de estímulos visuais, de variação no modo de transmitir } \\
\text { conhecimento, gostam de aulas participativas aonde eles não são meros receptores." }\end{array}$ \\
\hline & “[...] uma boa metodologia é que pode despertar realmente o interesse do aluno" \\
\hline & "Ferramenta 'chave' para atingir o objetivo." \\
\hline \multirow{5}{*}{$\begin{array}{c}10 \text { a } 15 \\
\text { anos }\end{array}$} & $\begin{array}{l}\text { "A metodologia utilizada tem toda a influência positiva quando aplicada o método correto para a } \\
\text { disciplina específica. Deve-se analisar método x disciplina x curso, esses devem caminhar juntos para } \\
\text { que tenhamos bons "resultados'." }\end{array}$ \\
\hline & $\begin{array}{l}\text { "É o ponto principal para atingir as metas propostas. Um bom preparo mais uma boa técnica é igual a } \\
\text { uma boa aula." }\end{array}$ \\
\hline & $\begin{array}{l}\text { "Processo direto e permite dinâmica diferenciada, que promove a comunicação, dinâmica na } \\
\text { transformação do indivíduo e aprimoramento profissional." }\end{array}$ \\
\hline & $\begin{array}{l}\text { "O escritório modelo pode ser uma aproximação maior com o mundo profissional real [...] há } \\
\text { diferentes barreiras para sua implantação e manutenção [...] o estágio poderia ser uma excelente } \\
\text { oportunidade, mas os escritórios não aderem" }\end{array}$ \\
\hline & $\begin{array}{l}\text { "A metodologia de ensino utilizada pode favorecer ou dificultar a aprendizagem. Não há uma única } \\
\text { metodologia que pode ser considerada a mais adequada. Um conjunto de metodologias combinadas e } \\
\text { aplicadas adequadamente, podem favorecer as condições para aprendizagem dos diferentes conteúdos } \\
\text { abordados no ensino de contabilidade." }\end{array}$ \\
\hline \multirow[b]{2}{*}{$\begin{array}{l}15 \text { a } 20 \\
\text { anos }\end{array}$} & "A metodologia permite um processo de ensino/aprendizagem mais estruturado e consistente." \\
\hline & $\begin{array}{l}\text { "[...] o professor deve aplicar metodologias de ensino diferentes [...] o importante é o professor saber } \\
\text { julgar qual metodologia é mais adequada para aquele conteúdo, ou até mesmo, para determinada } \\
\text { turma." }\end{array}$ \\
\hline \multirow{3}{*}{$\begin{array}{c}20 \text { a } 25 \\
\text { anos }\end{array}$} & "A metodologia permite um processo de ensino/aprendizagem mais estruturado e consistente." \\
\hline & "Imprescindível." \\
\hline & $\begin{array}{l}\text { "Acredito que a metodologia pode estimular o aluno a gostar mais de um tema ou disciplina em } \\
\text { detrimento de outra. Tal influência pode, inclusive, estimular o aluno a seguir campos específicos de } \\
\text { atuação ou despertar algum." }\end{array}$ \\
\hline
\end{tabular}

Fonte: Dados da Pesquisa

Estes resultados foram diferentes das expectativas do Amoor (2010) e Schreuder (2014) de que o tempo de experiência dos professores afeta a percepção docente sobre a aprendizagem. Ressalta-se que 87,50\% dos docentes relataram participar de curso e/ou outras atividades de aprimoramento de formação docente. Os achados de pesquisa vão ao encontro as explicações do Howieson et al. (2014), de que a educação em contabilidade ainda enfatiza a formação de um profissional com concepções meramente técnicas e que se limita à regras e desempenho de tarefas rotineiras.

De acordo aos resultados sobre a percepção docente, o ensino é voltado a aproximar a teoria com a prática contábil de forma mecânica. $\mathrm{O}$ discurso pedagógico dos docentes demonstra acepção ao conhecimento baseado na acumulação de conteúdo. Torna-se relevante, nesse sentido, repensar a forma de ensino, uma vez que os órgãos internacionais de contabilidade e diversos pesquisadores (LOMBAERTS et al., 2009; BECKER, 2011; MOOS; RINGDAL, 2012) apontam como necessário a formação de profissionais que saibam lidar com 
a incerteza e possuam habilidades na resolução de problema, além da acumulação do conteúdo técnico.

\subsection{Relacionar o perfil de aprendizagem dos alunos aos métodos educacionais de ensino registrados e relatados e a percepção docente do curso de ciências contábeis}

Os achados permitem inferir que a influência da metodologia de ensino e a percepção docente sobre a aprendizagem podem incentivar o desenvolvimento de atitudes independentes e pensamento crítico, uma vez que o aluno ingressante e o aluno formando apresentam diferença significativa sobre o nível de de utilização de estratégia cognitiva, como apontam Boekaerts e Corno (2005) e Becker (2011; 2013).

Os docentes aparentam possuir discernimento sobre os métodos que podem contribuir no desenvolvimento de habilidades metacognitivas, sobretudo ao relatar os métodos que proporcionam melhor aprendizagem e sua justificativa de uso. Entretanto esses métodos escolhidos como os melhores não são os mesmos relatados como os utilizados. Os métodos relatados como os melhores se aproximam da abordagem centrada na aprendizagem, já os métodos relatados como utilizados se aproximam de uma mescla entre a abordagem centrada no conteúdo e na aprendizagem.

Percebe-se a existência de um gap entre os métodos de ensino relatados como os melhores com relatados como utilizados. Os fatores apresentados na literatura da abordagem centrada no conteúdo explicam que o professor não pode, tem receio de utilizar métodos de ensino interativos ou o método educacional é escolhido de acordo ao que é confortável ao docente.

$\mathrm{Na}$ análise da percepção docente sobre a aprendizagem, os professores demonstram percepção da aprendizagem com mais características da pedagogia tradicional do que da andragogia. $\mathrm{O}$ discurso desses docentes sugere não ter intenção de tornar o discente aprendiz autônomo e com habilidade de pensamento crítico e sim apenas voltada a preparação técnica da profissão contábil. Nesse sentido, pode-se inferir que a utilização de múltiplos métodos de ensino tem apenas a consecução de aproximar o conteúdo teórico com o conteúdo técnico e prático da contabilidade.

Como implicação, a percepção docente sobre a aprendizagem apenas enfatiza à formação de um profissional com concepções meramente técnicas, o que se limita às regras e desempenho de tarefas rotineiras de contabilidade. Assim, não possui o discurso de preparar o discente para se adaptar aos contextos de mudanças acadêmicas e profissionais em contabilidade, para aprender conteúdos desconhecidos, a se tornar aprendiz permanente e, sobretudo, possuir pensamento crítico.

Entretanto, ao utilizar diferentes métodos de ensino, mescla entre os métodos ativos e passivos, pode ter contribuído no desenvolvimento de nível maior de estratégias metacognitivas de aprendizagem autorregulada. Contudo, a diferença média no nível de utilização de estratégia entre os discentes de fase inicial e final variou de apenas 4,76 para 5,12, o que não demonstra uma diferença considerável. Nesse sentido, a utilização dos métodos de ensino sem a percepção de contribuir com o aumento de estratégia metacognitivas pode ter influenciado em não se obter níveis maiores.

\section{Conclusão}

Tais constatações permitem inferir que a influência da metodologia educacional de ensino e a percepção docente sobre a aprendizagem podem incentivar o desenvolvimento de atitudes independentes e pensamento crítico, como apontam Zimmerman (2001), Lombaerts et al. (2008), Becker (2011) e Moos e Ringdal (2012). Os métodos de ensino utilizados pelos 
professores se aproximam de uma mescla entre a abordagem centrada no conteúdo e na aprendizagem e sua percepção sobre a aprendizagem demonstra predominância de característica da pedagogia tradicional em detrimento à andragogia.

Ao considerar a existência de um gap entre os métodos de ensino relatados como os melhores e os relatados como utilizados e percepção docente sobre a aprendizagem, conclui-se que o ensino tem apenas a consecução de aproximar o conteúdo teórico com o conteúdo técnico e prático da contabilidade. Entretanto, ao utilizar diferentes métodos de ensino, mescla entre os métodos ativos e passivos, pode ter contribuído no desenvolvimento de nível maior de estratégias metacognitivas de aprendizagem autorregulada.

Tem-se como implicação, a percepção docente sobre aprendizagem que enfatiza à formação de um profissional com concepções meramente técnicas, o que se limita às regras e desempenho de tarefas rotineiras de contabilidade. E, assim, não possui o discurso de preparar o discente para se adaptar aos contextos de mudanças acadêmicas e profissionais em contabilidade, para aprender conteúdos desconhecidos, a se tornar aprendiz permanente e, sobretudo, possuir pensamento crítico.

Algumas das limitações apontadas nesse estudo também se apresentam como sugestões e recomendações para novas investigações, tais como contemplar os demais professores, de outras disciplinas, que também lecionam em Ciências Contábeis, mas que são de outras áreas e, dessa forma, decompor as análises de resultados de acordo a área de formação. Outra necessidade de ampliação da pesquisa está em buscar evidência sobre quais os impactos que a experiência profissional docente e não docente exerce sobre a percepção de aprendizagem. Ainda, sugere-se realizar esse mesmo estudo em instituições com distintos resultados no Enade, para comparar resultados com as abordagens metodológicas em sala de aula, bem como, relacionar o discurso sobre os melhores métodos com o uso efetivo em sala de aula.

\section{Referências}

ACCOUNTING EDUCATION CHANGE COMMISSION (AECC). Objectives of education for accountants: Position statement number one. Issues in Accounting Education: 307-312, 1990.

\section{AMERICAN INSTITUTE OF CERTIFIED PUBLIC ACCOUNTANTS (AICPA). Core}

Competency Framework for Entry into the Accounting Profession. 2010.

AMERICAN INSTITUTE OF CERTIFIED PUBLIC ACCOUNTANTS (AICPA). Core Competency Framework for Entry into the Accounting Profession. 2000.

AMOOR, S. S. The need to improve teacher quality in business education programme in Nigerian universities. International Journal of Educational Research, v. 11, n. 1, p. 1-12, 2010.

ANDRADE, Cacilda Soares de. $\mathbf{O}$ ensino de contabilidade introdutória nas universidades públicas do Brasil. 2002. Fl55. Dissertação (Mestrado em Controladoria e Contabilidade) Universidade de São Paulo, 2002. https://doi.org/10.11606/d.12.2002.tde-11112004-140947

BLACK, W. H. The activities of the pathways commission and the historical context for changes in accounting education. Issues in Accounting Education. v. 27, n. 3, p. 601-625, 2012. https://doi.org/10.2308/iace-50091

BECKER, L. L. Self-Regulated Learning in an Introductory Undergraduate Accounting Course. Tese (Doutorado em Educação em Liderança), 179 f., Universidade Estadual do Leste de Tennessee, EUA, 2011. 
BECKER, L. L. Self-Regulated Learning Interventions in the Introductory Accounting Course: An Empirical Study. Issues in Accounting Education, v. 28, n. 3, p. 435-460, 2013. https://doi.org/10.2308/iace-50444

BOEKAERTS, Monique; CORNO, Lyn. Self-regulation in the classroom: A perspective on assessment and intervention. Applied Psychology, v. 54, n. 2, p. 199-231, 2005. https://doi.org/10.1111/j.1464-0597.2005.00205.x

BORGES, M. P. P.; LEAL, E. A. Estratégias e Métodos Aplicados no Ensino da Contabilidade Gerencial: Um Estudo com Discentes do Curso de Ciências Contábeis. In: I Congresso UFU de Contabilidade, 2015, Uberlândia-MG. I Congresso UFU de Contabilidade, 2015.

BORKO, Hilda. Professional development and teacher learning: Mapping the terrain. Educational researcher, v. 33, n. 8, p. 3-15, 2004.

BORUCHOVITCH, E. Algumas estratégias de compreensão da leitura de aluno de ensino fundamental. Psicologia Escolar e Educacional, v. 5, n. 1, p. 19-26, 2001. https://doi.org/10.1590/s1413-85572001000100003

BYRNE, Marann; FLOOD, Barbara; WILLIS, Pauline. An Inter-Institutional Exploration of the Learning Approaches of Students Studying Accounting. International Journal of Teaching and Learning in Higher Education, v. 20, n. 2, p. 155-167, 2009.

CARVALHO, Jair Antonio de; CARVALHO, Marlene Pedrote de; BARRETO, Maria Auxiliadora Motta; ALVES, Fábio Aguiar. Andragogia: Considerações sobre a aprendizagem do adulto. REMPEC - Ensino, Saúde e Ambiente, v.3, n 1, p. 78-90, Abril 2010. https://doi.org/10.22409/resa2010.v3i1.a21105

CATTELL, R. B. The scree test for the number of factors. Multivariate Behavioral Research, v. 1, p. 245-267, 1966. https://doi.org/10.1207/s15327906mbr0102_10

CHIHEVE, Herbert. Self-Directed Learning In Accounting Education In Polytechnics In Zimbabwe. International Journal of Innovative Research and Development, v. 2, n. 9, 2014.

COSENZA, José Paulo, Perspectivas para a Profissão Contábil num Mundo Globalizado Um Estudo a Partir da Experiência Brasileira, Revista Brasileira de Contabilidade RBC, Jul/Ago $2001-\mathrm{n}^{\circ} 130$.

COETZEE, S. A.; SCHMULIAN, A. A critical analysis of the pedagogical approach employed in an introductory course to IFRS. Issues in Accounting Education. v. 27, n. 1, p. 83-100, 2012.

CORNO, Lyn. Self-regulated learning: A volitional analysis. In: Self-regulated learning and academic achievement. Springer New York, 1989. p. 111-141. https://doi.org/10.1007/9781-4612-3618-4_5

DARLING-HAMMOND, Linda; MCLAUGHLIN, Milbrey W. Policies that support professional development in an era of reform. Phi delta kappan, v. 76, n. 8, p. 597-604, 1995.

DRAKE, John R. A critical analysis of active learning and an alternative pedagogical framework for introductory information systems courses.Journal of Information Technology Education, v. 11, p. 39-52, 2012.

DEAQUINO, Carlos Tasso Eira. Como aprender: andragogia e as habilidades de aprendizagem. Pearson Prentice Hall, 2007.

DEMETRIOU, Andreas. Organization and development of self-understanding and selfregulation: Toward a general theory, 2000. 
DENZIN, N. K.; LINCOLN, Y. S. O planejamento da pesquisa qualitativa: teorias e abordagens. Porto Alegre: Artmed, 2006.

EBOLI, Marisa. Educação Corporativa. Revista T\&D-Inteligência Corporativa, v. 137, n. 12, p. 48, 2004.

HAIR, Joseph F. et al. Multivariate data analysis. 1998.

HAMZE, A. Andragogia e a arte de ensinar aos adultos. Disponível em http://www.educador.brasilescola.com/trabalhdocente/andragogia.htm. Acessado em $14 / 06 / 2015$

HOWIESON, Bryan et al. Who should teach what? Australian perceptions of the roles of universities and practice in the education of professional accountants. Journal of Accounting Education, v. 32, n. 3, p. 259-275, 2014. https://doi.org/10.1016/j.jaccedu.2014.05.001

LEAL, Douglas Tavares Borges; CORNACHIONE JR, Edgard. A aula expositiva no ensino da contabilidade. Contabilidade vista \& revista, v. 17, n. 3, p. 91-113, 2006.

LEAL, Edvalda Araujo; BORGES, A.V.S. Estratégias e Métodos Aplicados no Ensino da Contabilidade: uma análise dos Planos de Ensino do Curso de Ciências Contábeis de Uma Instituição Pública Brasileira. In: VIII Congresso ANPCONT, 2014, Rio de Janeiro. VIII Congresso ANPCONT, 2014.

LIMA FILHO, R. N.; LIMA, G. A. S. F.; BRUNI, A. L. Aprendizagem autorregulada em Contabilidade: diagnósticos, dimensões e explicações. Brazilian Business Review, v. 12, n. 1, p. 38-56, 2015.

LOMBAERTS, Koen; ENGELS, Nadine; VAN BRAAK, Johan. Determinants of teachers' recognitions of self-regulated learning practices in elementary education. The Journal of Educational Research, v. 102, n. 3, p. 163-174, 2009.

KNOWLES, Malcolm S.; HOLTON III, Elwood F.; SWANSON, Richard A.The adult learner: The definitive classic in adult education and human resource development. Routledge, 2014

KNOWLES, M. S., HOLTON III, E. F., AND SWANSON, R.A., A theory of adult learning: Andragogy. The adult learner: The definitive classic in adult education and human resource development, 5 th Ed., Houston: Gulf Publishing Company, 35-72, 1998.

KNOWLES, Charles O. Metabolism of two acaricidal chemicals, N'-(4-chloro-o-tolyl)-N, Ndimethylformamidine (chlorophenamidine) and $\mathrm{m}-\{[($ dimethylamino) methylene $]$ amino $\}$ phenyl methylcarbamate hydrochloride (formetanate). Journal of agricultural and food chemistry, v. 18, n. 6, p. 1038-1047, 1970. https://doi.org/10.1021/jf60172a044

MARTIN, A. J.; DOWSON, M. Interpersonal relationships, motivation, engagement, and achievement: Yields for theory, current issues, and educational practice. Review of educational research, v. 79, n. 1, p. 327-365, 2009.

https://doi.org/10.3102/0034654308325583

MADUREIRA, N. L.; SUCCAR Jr., F.; GOMES, J. S. Estudo sobre os métodos de ensino utilizados nos cursos de ciências contábeis e administração da universidade estadual do rio de janeiro (Uerj): a percepção de docentes e discentes. Revista de Informação Contábil, Rio de Janeiro, v. 5, n. 2, p. 43-53, 2011.

MIRANDA, G. J.; LEAL, E. A.; CASA NOVA, S. P. C. Técnicas de ensino aplicadas à contabilidade: existe uma receita? In: COIMBRA, C. L. Didática para o ensino nas áreas de administração e ciências contábeis. São Paulo: Atlas, 2012. 
MOENIKIA, M; ABTIN, J. Relationship between using of ICT and psychological characteristics in Ardabil secondary schools' students. Iran, Ardabil, educational organization, 2006.

MOOS, D. C.; RINGDAL, A. Self-regulated learning in the classroom: A literature review on the teacher's role. Education Research International, v. 2012, 2012.

NETEMEYER, Richard G.; BEARDEN, William O.; SHARMA, Subhash. Scaling procedures: Issues and applications. Sage Publications, 2003.

NIEMI, H., HARJU, V., VIVITSOU, M., VIITANEN, K., MULTISILTA, J., \& KUOKKANEN, A. Digital Storytelling for 21 st-Century Skills in Virtual Learning Environments. Creative Education, 2014. https://doi.org/10.4236/ce.2014.59078

NOFFS, Neide de Aquino; RODRIGUES, Carla Maria Rezende. Andragogia na Psicopedagogia: a atuação com adultos. Revista Psicopedagogia, v. 28, n. 87, p. 283-292, 2011.

NGANGA, C. S. N.; FERREIRA, M. A.; NETO, E. B. M. N.; LEAL, E. A. L. Estratégias e técnicas aplicadas no ensino da contabilidade gerencial: um estudo com docentes do curso de ciências contábeis. In: ENCONTRO DE ENSINO E PESQUISA EM ADMINISTRAÇÃO E CONTABILIDADE, 4., 2013, Brasília. Anais... Brasília, 2013. CD-ROM.

NGWENYA, J.C.; MAISTRY, S.M. Teaching and assessment in accounting: An exploration of teachers' experiences in a rural KwaZulu-Natal School. Journal of Social Sciences, v. 33, n. 1, p. 21-30, 2012.

OPDECAM, Evelien; EVERAERT, Patricia. Improving student satisfaction in a first-year undergraduate accounting course by team learning. Issues in Accounting Education, v. 27, n. 1, p. 53-82, 2012.

POSTAREFF, Liisa; LINDBLOM-YLÄNNE, Sari. Variation in teachers' descriptions of teaching: Broadening the understanding of teaching in higher education. Learning and Instruction, v. 18, n. 2, p. 109-120, 2008.

RAGOSTA, Patrick. The effectiveness of intervention programs to help college students acquire self-regulated learning strategies: A meta-analysis. City University of New York, 2010.

RIBEIRO, L. R. C.; ESCRIVÃO FILHO, E.; MIZUKAMI, M. G. N. Uma experiência com a PBL no ensino de engenharia sob a ótica dos alunos. Revista de Ensino de Engenharia, v.23, n.1, p.63-17, 2004.

ROMANOWSKY, Luis Roberto; BEUREN, Ilse Maria. Um Estudo dos Procedimentos Metodológicos de Ensino Utilizado nos Cursos de Ciências Contábeis. Revista Brasileira de Contabilidade. Setembro/Outubro 2002.

ROSÁRIO, Pedro. Diferenças processuais na aprendizagem: avaliação alternativa das estratégias de auto-regulação da aprendizagem. 2001.

ROSÁRIO, Pedro. Estudar o estudar: As (Des) venturas do Testas. Porto: Porto Editora, 2004.

SCHLEIFER, L. F.; DULL, R. B. Metacognition and performance in the accounting classroom. Issues in Accounting Education, n. 3, p. 44-68, 2009.

SCHMIDT, Elisabeth Silveira. Currículo: uma abordagem conceitual e histórica. Publicatio UEPG: Ciências Humanas, Linguistica, Letras e Artes, v. 11, n. 1, 2003. https://doi.org/10.5212/publicatiohum.v.16i1.061065 
SCHREUDER, Glynis Rholeen. Teacher Professional Development: The Case Of Quality Teaching In Accounting At Selected Western Cape Secondary Schools. Tese de Doutorado. Cape Peninsula University of Technology, 2014.

SCHUNK, D. H. Commentary on self-regulation in school contexts.Learning and Instruction, v. 15, n. 2, p. 173-177, 2005.

SHULMAN, Lee. Knowledge and teaching: Foundations of the new reform.Harvard educational review, v. 57, n. 1, p. 1-23, 1987.

SILVA, Thiago Bruno de Jesus. Estratégia Metacognitiva de Aprendizagem Autorregulada, Percepção Docente Sobre a Aprendizagem e Métodos Educacionais Em Contabilidade: Estudo de caso em uma universidade pública catarinense. 2016. $97 \mathrm{f}$. Dissertação (Mestrado em Ciências Contábeis) - Programa de Pós-Graduação em Ciências Contábeis da Universidade Regional de Blumenau, Blumenau (SC), 2016.

SPERLING, R. A., B. C. HOWARD, R. STALEY, AND N. DUBOIS. Metacognition and self-regulated learning constructs. Educational Research and Evaluation 10 (2): 117-139, 2004. https://doi.org/10.1076/edre.10.2.117.27905

SOARES, Mara Alves. Aplicação do método de ensino Problem Based Learning (PBL) no curso de ciências contábeis: um estudo empírico. 2008. Tese de Doutorado. Universidade de São Paulo.

STANLEY, Trevor; MARSDEN, Stephen. Problem-based learning: Does accounting education need it?. Journal of Accounting Education, v. 30, n. 3, p. 267-289, 2012.

TUYSUZOGLU, B. B. An investigation of the role of metacognitive behavior in selfregulated learning when learning a complex science topic with a hypermedia learning environment. Tese de Doutorado. The University of North Carolina at Chapel Hill, 2011.

VILLEGAS-REIMERS, Eleonora et al. Teacher professional development: an international review of the literature. Paris: International Institute for Educational Planning, 2003.

ZIMMERMAN, B. J. Theories of self-regulated learning and academic achievement: An overview and analysis. NJ: Lawrence Erlbaum Associates, 2001.

ZIMMERMAN, B. J. Becoming a self-regulated learner: Which are the key subprocesses?

Contemporary Educational Psychology, n.11, p. 307-313, 1986.

https://doi.org/10.1016/0361-476x(86)90027-5

ZIMMERMAN, B. J.; PONS, M. M. Development of a structured interview for assessing student use of self-regulated learning strategies. American educational research journal, v. 23, n. 4, p. 614-628, 1986. https://doi.org/10.3102/00028312023004614

ZRAA, Wahida; HARTLE, R. Todd; KAVANAGH, Marie. Adopting appropriate teaching models to develop knowledge and skills to academic standards in the accounting discipline. In: Proceedings of the 2011 AFAANZ Conference. Accounting \& Finance Association of Australia and New Zealand, 2011. p. 1-23. 